\title{
Integrins regulate stemness in solid tumor: an emerging therapeutic target
}

\author{
Jiangling Xiong ${ }^{1,2 \dagger}$, Lianlian Yan ${ }^{1,2 \dagger}$, Cheng Zou ${ }^{1,2 \dagger}$, Kai Wang $^{3 \dagger}$, Mengjie Chen ${ }^{1,2}$, Bin Xu ${ }^{3 *}$, Zhipeng Zhou ${ }^{4^{*}}$ and
} Dingxiao Zhang ${ }^{1,2^{*}}$ (1)

\begin{abstract}
Integrins are the adhesion molecules and transmembrane receptors that consist of $a$ and $\beta$ subunits. After binding to extracellular matrix components, integrins trigger intracellular signaling and regulate a wide spectrum of cellular functions, including cell survival, proliferation, differentiation and migration. Since the pattern of integrins expression is a key determinant of cell behavior in response to microenvironmental cues, deregulation of integrins caused by various mechanisms has been causally linked to cancer development and progression in several solid tumor types. In this review, we discuss the integrin signalosome with a highlight of a few key pro-oncogenic pathways elicited by integrins, and uncover the mutational and transcriptomic landscape of integrin-encoding genes across human cancers. In addition, we focus on the integrin-mediated control of cancer stem cell and tumor stemness in general, such as tumor initiation, epithelial plasticity, organotropic metastasis and drug resistance. With insights into how integrins contribute to the stem-like functions, we now gain better understanding of the integrin signalosome, which will greatly assist novel therapeutic development and more precise clinical decisions.
\end{abstract}

Keywords: Integrin, Stemness, Solid tumor, Cancer stem cells, Metastasis, Therapeutic targeting

\section{Introduction}

The term of integrin was first used to describe the receptor's function of integrating the extracellular matrix (ECM) network to the cellular cytoskeletal network. As members of the membrane glycoprotein superfamily, integrins are transmembrane (TM) cell surface heterodimeric receptors consisting of an $\alpha$ and a $\beta$ subunit. There are $18 \alpha$ subunits and $8 \beta$ subunits in mammals, which to date form $24 \alpha \beta$ integrin heterodimers [1]. Importantly,

\footnotetext{
*Correspondence: xb15896450810@126.com; zhouzhipeng@mail.hzau.edu. cn; zdx1980@hnu.edu.cn

†Jiangling Xiong, Lianlian Yan, Cheng Zou, Kai Wang have contributed equally.

${ }^{1}$ School of Biomedical Sciences, Hunan University, Changsha 410082, Hunan Province, China

${ }^{3}$ Department of Urology, School of Medicine, Affiliated Zhongda Hospital of Southeast University, Nanjing 210009, Jiangsu Province, China

${ }^{4}$ College of Life Science and Technology, Huazhong Agricultural University, Wuhan 430070, Hubei Province, China

Full list of author information is available at the end of the article
}

each pair of heterodimers display both functional and tissue specificity involved in a plethora of biological processes in development and disease [2]. The assortment of integrin repertoire allows for adhesion to nearly all ECM components; and depending on different types of ligands, integrins can be classified mainly into four categories: (1) receptors that recognize the tripeptide RGD (Arg-Gly-Asp) sequence (including all five $\alpha v$ integrins, two $\beta 1$ integrins $(\alpha 5, \alpha 8)$ and $\alpha \operatorname{IIb} \beta 3)$; (2) receptors that are leukocyte-specific and bind to LDV (L/I-D/E-V/S/ $\mathrm{T}-\mathrm{P} / \mathrm{S}$ ) sequences (including two $\alpha 4$ integrins $(\beta 1, \beta 7)$, $\alpha 9 \beta 1, \alpha E \beta 7$ and four members of $\beta 2$ integrins); (3) receptors that bind selectively to laminin (including $\alpha 6 \beta 4$ and three $\beta 1$ integrins $(\alpha 3, \alpha 6, \alpha 7)$ ); and (4) collagen-binding receptors (including four $\beta 1$ integrins $(\alpha 1, \alpha 2, \alpha 10, \alpha 11)$ recognizing $\mathrm{G}-\mathrm{F}-\mathrm{O}-\mathrm{G}-\mathrm{E}-\mathrm{R}$ motif). Basically, the first category is RGD-dependent and the rest three are RGDindependent. Besides ECM molecules, integrins also bind to counter-receptors on the surface of neighboring cells, 
such as lg-superfamily cell surface receptor vascular cell adhesion molecule-1 (VCAM-1) and intercellular adhesion molecule-1 (ICAM-1) [3]. In general, through cognate ligand binding, integrins sense and trigger distinct intracellular signaling cascades in response to extracellular changes, which are frequently essential for physiological and pathological functions [4]. Notably, and interestingly, different categories of integrins can recognize and bind the same ligands, and the same integrins can bind to multiple distinct ligands [2], indicative of an intricate network of integrin signalosome. Here, we discuss the origins and consequences of deregulated integrin signaling in solid cancers, with an emphasis on their regulation in cancer stemness and therapeutic resistance. By summarizing the current situation of anti-integrin agents in pre-clinical and clinical practice, we also illustrate emerging mechanism-based therapeutic strategies to combat life-threatening cancers.

\section{Structure and working model of integrins}

Despite the diversity of integrin heterodimers, integrins are evolutionally conserved in amino acid (aa) sequences and share a common structure (i.e., a large extracellular domain, a short transmembrane domain and a short cytoplasmic domain). The extracellular regions of both $\alpha$ and $\beta$ subunits participate in ligand binding (Fig. 1a). Half of the $18 \alpha$-subunits $(\alpha 1, \alpha 2, \alpha 10, \alpha 11, \alpha \mathrm{D}, \alpha \mathrm{L}, \alpha \mathrm{M}$, $\alpha \mathrm{X}$ and $\alpha \mathrm{E})$ have an additional 200aa I-domain inserted in the $\beta$-propeller domain [5]. The $\alpha \mathrm{I}$-domain possesses a metal ion-dependent adhesion site (MIDAS), the major binding site for ligands such as collagen and some laminins [6]. Similarly, the $\beta$ subunit generally comprises of a plexin-sempahorin-integrin (PSI) domain, a hybrid domain (with an I-like domain, called $\beta I$, embedded in), an integrin epidermal growth factor-like (I-EGF) domain and a $\beta$-tail domain (Fig. 1a). The $\beta I$-domain is analogous to the $\alpha \mathrm{I}$-domain and participates in ligand binding by interacting with $\beta$-propeller domain in another $9 \alpha$-integrins without $\alpha \mathrm{I}$-domain $(\alpha 3, \alpha 4, \alpha 5, \alpha 6, \alpha 7, \alpha 8$, $\alpha 9, \alpha v$ and $\alpha \mathrm{IIb}$ ) [7]. The transmembrane helical domains (TMD) of the $\alpha$ and $\beta$ subunits are conservative and an association between $\alpha$-TMD and $\beta$-TMD directly correlates with integrin activation. Integrin cytoplasmic tails serve as nucleation center for integrin and intercellular protein interactions. Except the $\beta 4$ tail which is approximately 1000aa long, the lengths of the $\alpha$ and $\beta$ cytoplasmic tails are usually less than 75aa. Particularly, and unlike the other integrins, $\beta 4$ integrin couples to the intermediate filament instead of actin cytoskeleton [8]. Most integrin $\beta$ tails contain a NPxY/F motif, rendering binding to phosphotyrosine binding (PTB) domainscontaining proteins such as Talin. Notably, the homology among $\beta$ subunit cytoplasmic tails is strikingly high,

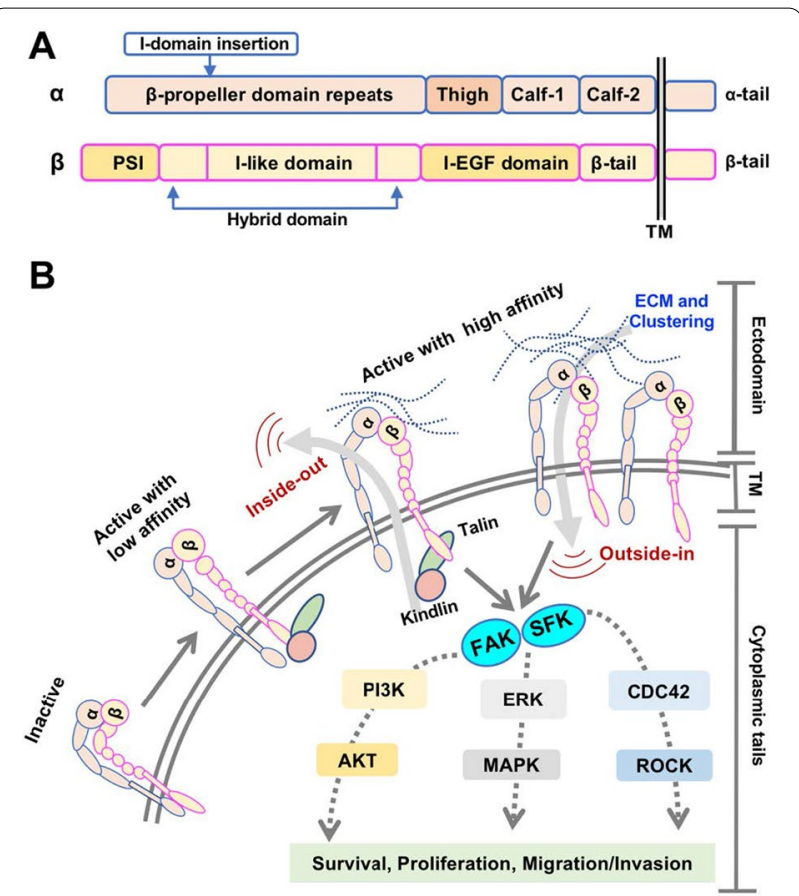

Fig. 1 Integrin structure and integrin signalosome. a Schematic domain structure of a generic integrin. The a subunit contains 8 $\beta$-propeller domain repeats, a thigh domain, two calf domains (Calf-1 and (Calf-2) and an a-tail domain. Notably, for 9 out of 18 a subunits, there is an I-domain inserted between $\beta$ propeller domains 2 and 3 .

The $\beta$ subunit typically comprises a plexin-semaphorin-integrin (PSI) domain, an I-like domain followed by a $\beta$-sandwich hybrid domain, four cysteine-rich integrin epidermal growth factor-like (I-EGF) repeats and a $\beta$-tail domain. b Bidirectional integrin signalosome. Integrins exist in different conformational states that determine the receptor affinity for ECM components and other ligands: from a bent-closed (inactive) to an extended closed (active with low affinity) and finally to an extended open conformation (active with high affinity). When binding to ECM proteins, integrins are activated and clustered, and are capable of eliciting downstream signaling and controlling cellular responses to environmental cues (outside-in signaling). Integrins also response to an "inside-out signaling", whereby Talin binding to the $\beta$ integrin tail triggers conformational switch to an extended open state and further recruit integrin activating proteins such as Kindlins to activate integrin. The most well-studied hub pathway activated by integrins is focal adhesion kinase (FAK), with subsequent recruitment and activation of the Src family kinase (SFK), which ultimately affects cell behavior via crosstalk with many other signaling effectors. See text for details

whereas $\alpha$ tails are highly divergent except for a conserved GFFKR motif located next to the TM region.

It is widely accepted that integrin activation is a multistep process accompanied with conformational changes. Structural studies have revealed that integrins have three conformation states (Fig. 1b): bent-closed (inactive), extended-closed (active with low affinity), and extendedopen (active with high affinity) [4,9]. In the inactive state, an integrin extracellular region is bent and the 
cytoplasmic tails of $\alpha$ and $\beta$ subunits are closed together. The interaction between $\alpha$ and $\beta$ tails further stabilizes the inactive conformation [9]. Upon binding to an adaptor protein Talin (a high molecular weight cytoskeletal protein concentrated at regions of cell-substratum contact) and/or Kindlin (an integrin-binding co-activator), $\beta$ integrin tail is forced to separate, leading to an unfolding of the TM and extracellular domains that creates availability of a ligand binding pocket (active with low affinity) $[4,9]$. Upon engaging the ECM, integrin straightens out and further separates the cytoplasmic tails. This conformational change permits the receptor to interact with cytoskeletal proteins and signal transducers (active with high affinity). In turn, these interactions further enhance the ligand-binding affinity and induce clustering of other activated integrins to facilitate strong focal adhesion formation [10]. This adhesion complexes connect intracellular cytoskeleton to the basement membrane by indirect integrin-actin connections (e.g., the $\alpha 6 \beta 4$ integrin associates with intermediate filament). Notably, mechanical forces assist reinforcement of the ECM-cytoskeleton link and recruitment of additional signaling proteins to activate integrin [11].

Integrins have no enzymatic activity and thus depend on binding to neighboring receptors and intracellular proteins to transmit mechanical and chemical signals to the cell interior and finally affect cellular functions. Approximately 150 adhesion proteins have been identified in part of integrin-mediated adhesion complex, which is known as focal adhesion or adhesome [4, 12]. Thus, the downstream signaling of an active integrin (i.e., integrin signalosome) is complex and cell specific, but typically involves autophosphorylation of the focal adhesion kinase (FAK) and subsequent recruitment and activation of Src family kinase (SFK) (Fig. 1b) [12]. FAK is a key signaling effector and can be activated by most integrins. It can interact directly, or indirectly through Talin and Paxillin, with the cytoplasmic tail of $\beta$ subunits. FAK recruits the growth factor receptor bound protein 2 (GRB2) and actives Ras-ERK (extracellular signal regulated kinase)/MAPK (mitogen activated protein kinase) cascade to promote cell cycle progression and proliferation [13]. FAK can also interact with and activate phosphoinositide 3-OH kinase (PI3K), leading to activation of its downstream effectors, particularly AKT, and promotion of cell migration and invasion [14]. Moreover, with or without the assistance of FAK, SFK could phosphorylate additional substrates, impinging on multiple pro-mitogenic or pro-survival pathways including the Ras-ERK and PI3K-AKT pathways [4]. Additionally, FAKand SFK-regulated Rac and Cdc42 signaling can activate ARP2/3 complex and LIM kinase to induce actin polymerization, which is necessary for cell migration [15].
Functionally, integrin mediates bidirectional signal crosstalk including "outside-in" signaling where ECMengaged activation of integrin triggers focal adhesion formation, and "inside-out" signaling where signals inside the cell (e.g., Talin and Kindlin biding) activate the integrin for binding to the extracellular ligands [4, 16]. Through this bidirectional linkage, integrins provide communication between cell and microenvironment, function as a mechano-sensor and force transducer, and coordinate actin cytoskeleton to modulate an array of important biological processes such as cell adhesion, migration, proliferation, differentiation, and apoptosis (Fig. 1b), which are frequently mis-regulated in cancers.

\section{Roles of integrins in solid cancer}

Cancer is a dynamic developmental disorder. Evidence from in vivo genetic studies has established integrins as vital factors regulating development [17]. Consistently, there are several human diseases linked to defects in integrin signaling (e.g., loss of $\beta 2$ integrin function leads to an autosomal recessive disorder of the immune system called leucocyte adhesion deficiency type 1 (LAD-1) [18]). Given their important roles in diverse development contexts, integrins are expected to play pivotal roles in cancer development and progression (Table 1). For example, mice lacking $\beta 3$ integrins or both $\beta 3$ and $\beta 5$ integrins not only support tumorigenesis, but have enhanced tumor growth as well [19]. Under hostile conditions, tumor cells are generally able to repurpose the multifarious functions of integrins to favor their survival, proliferation and migration (Fig. 1b). Indeed, accumulating evidence has indicated, undeniably, that integrins are involved in almost every step of cancer development, including cancer initiation and proliferation, local invasion and intravasation into vascular system, survival of circulating tumor cells (CTCs) in the blood stream, priming of the metastatic niche, extravasation into the secondary site and metastatic colonization of the new tissue (see $[12,20]$ for more detail). Importantly, integrinmediated pathways are also frequently connected to the development of drug resistance [12]. A key property that endows integrin with such pro-tumorigenic or oncogenic functions is that they often regulate stemness, thus eventually facilitating tumor progression.

\section{Pan-cancer mutational landscape of genes encoding integrins}

Changes in the ECM and the repertoire of integrins on tumor cells contribute to deregulation of integrin signaling in cancer [4]. Altered integrin expression patterns have been frequently observed in, and also causally linked to, diverse types of cancers [12]. Examples of the roles of integrins played in human cancers are summarized 
in Table 1. While the majority of investigated integrins are pro-tumorigenic, there are ones suppressing tumor development and/or metastasis. For instance, in breast cancer $(\mathrm{BCa})$, while most $\beta 1$ integrins, and more specifically $\alpha 3 \beta 1$ integrin, are necessary for mammary tumorigenesis [21], $\alpha 2 \beta 1$ integrin (a receptor for collagen and other matrix molecules that highly expresses in normal breast epithelium) is a metastasis suppressor (but with little impact on primary tumor growth) in a mouse model of $\mathrm{BCa}$ [22]. To systematically uncover the underlying mechanisms of integrin dysregulation, we surveyed the mutational landscape of 26 genes encoding all human integrins across 32 human cancer types offered by current The Cancer Genome Atlas (TCGA) DNA sequencing effort through cBioPortal [23]. Results showed that integrin pathway represents, collectively, a frequently mutated pathway in human cancers with an average rate of $33.4 \%$ (Fig. 2a), ranging from $6.0 \%$ in thyroid carcinoma (THCA) to $70.05 \%$ in skin cutaneous melanoma (SKCM). However, the mutation frequency is very low at individual gene level (average of 3.0\%) (Fig. 2b), suggesting a limited contribution of genomic alteration to the transcriptomic dysregulation. Notably, amplification represents one of the main forms of alterations (e.g., in ovarian (OV), uterine (UCS), breast (BRCA) tumors) (Fig. 2a), potentially suggesting that a global upregulation of integrins may be tumorigenic.

To gain a better understanding of the potential roles played by individual integrins in different cancer-contexts, we chose ITGA10 and ITGA1 for further analysis in detail. Interestingly, ITGA10, encoding the $\alpha 10$ integrin, is the most amplified gene in a number of cancers (Fig. 2c), and consistent with this genomic alteration, it is consequently dysregulated in the majority of cancers (Fig. 2d). Differential gene expression analysis comparing tumor to normal tissues indicated that ITGA10 is markedly upregulated in sarcoma (SARC), SKCM and cholangiocarcinoma $(\mathrm{CHOL})$, potentially due to amplification (Fig. 2c, d). However, being highly amplified in a small proportion of patients bearing lung adenocarcinoma (LUAD), bladder urothelial carcinoma (BLCA), breast invasive carcinoma (BRCA) and lung squamous

Table 1 Integrin functions in different solid cancer types

\begin{tabular}{|c|c|c|c|c|}
\hline Integrin & Ligands/signaling partners & Cancer type & Function & References \\
\hline$\beta 1$ & Src/AKT & Lung & Promotes chemoresistance against EGFR inhibitor Erlotinib & {$[35]$} \\
\hline \multirow[t]{2}{*}{$a 2 \beta 1$} & Collagen type I & Prostate & Promotes prostate cancer cell invasion and skeletal metastasis & {$[36]$} \\
\hline & $\mathrm{CDH}-17$ & Colon & $\begin{array}{l}\text { Interacts with } \mathrm{CDH} 17 \text { to induce FAK and Ras activation and thus pro- } \\
\text { motes tumor growth and liver metastasis }\end{array}$ & {$[37]$} \\
\hline$a 3 \beta 1$ & Rho/Yap & CRPC & Suppresses anchorage-independent growth and metastasis & {$[38]$} \\
\hline a6 & AKT/ERK & Breast & $\begin{array}{l}\text { Expresses highly in breast cancer vs. normal cells and enhances radio- } \\
\text { therapy resistance }\end{array}$ & {$[39]$} \\
\hline a7 & Laminin & Glioblastoma & $\begin{array}{l}\text { Correlates negatively with patient survival and promotes growth and } \\
\text { invasiveness of CSCS }\end{array}$ & {$[40]$} \\
\hline$\alpha 9 \beta 1$ & $\beta$-catenin/E-cadherin & Lung & Promotes EMT, tumor growth, vasculogenesis and metastasis & {$[41]$} \\
\hline a10ß1 & Collagen and Laminin & Glioblastoma & $\begin{array}{l}\text { Upregulates in both glioblastoma tissue and cells, correlates with high- } \\
\text { grade gliomas, and promotes cell proliferation and migration }\end{array}$ & {$[42]$} \\
\hline$\beta 3$ & TGF $\beta$ & NSCLC & $\begin{array}{l}\text { Accelerates cancer cell adhesion to lymphatic endothelium after TGF- } \beta \\
\text { exposure, and combined targeting of } \beta 3 \text { integrin and TGF } \beta \text { reduces } \\
\text { lymph node metastasis }\end{array}$ & {$[43]$} \\
\hline \multirow[t]{3}{*}{$\operatorname{av\beta 3}$} & OPN/FAK & NSCLC & Enhances cell proliferation and EGFR-TKI resistance & {$[44]$} \\
\hline & Survivin & CRPC & $\begin{array}{l}\text { Promotes anchorage-independent cell growth and enhances IR resist- } \\
\text { ance via stabilization of Survivin }\end{array}$ & [45] \\
\hline & KRAS/RaIB & Lung/Breast/ Pancreas & $\begin{array}{l}\text { Recruits KRAS and RalB to activate TBK1 and NF-KB, leading to } \\
\text { enhanced stemness and RTK inhibitor resistance }\end{array}$ & {$[46]$} \\
\hline \multirow[t]{2}{*}{$\operatorname{av\beta 6}$} & MMP9 & SCC & Promotes invasion in an MMP9-dependent manner & {$[31]$} \\
\hline & JNK1/Survivin & CRPC & $\begin{array}{l}\text { Promotes anchorage-independent growth and cancer progression via } \\
\text { activation of androgen receptor }\end{array}$ & {$[28]$} \\
\hline$a 6 \beta 4$ & BNIP3L & TNBC & $\begin{array}{l}\text { Induces BNIP3L-dependent mitophagy and lactate production in CAFs, } \\
\text { which in turn promotes EMT, proliferation and invasion }\end{array}$ & {$[47]$} \\
\hline$\beta 8$ & ECM & PDAC & $\begin{array}{l}\text { Regulates positively cancer cell radiochemoresistance, intracellular } \\
\text { vesicle trafficking, and autophagy }\end{array}$ & {$[48]$} \\
\hline
\end{tabular}

CRPC Castration-resistant prostate cancer, CSCS cancer stem cells, EMT epithelial-mesenchymal transition, PDAC Pancreatic ductal adenocarcinoma, TNBC triple negative breast cancer, NSCLC Non-small-cell lung cancer, ECM extracellular matrix, TKI tyrosine kinase inhibitor, $R T K$ receptor tyrosine kinases, IR ionizing radiation, SCC squamous-cell carcinoma, CAFs cancer-associated fibroblasts 
cell carcinoma (LUSC), the expression of ITGA10 is conversely decreased in these tumors at population level (Fig. 2d), suggesting other mechanisms involved in its transcriptional regulation. Regardless of the genomic alterations, a prognostic value of an integrin is usually determined by its expression. Consistent with its upregulation in SARC and downregulation in BRCA, a higher level of ITGA10 correlated with poor and better patient survival, respectively (Fig. 2e). This highlights that ITGA10 functions in a cancer-specific manner. Moreover, although genomic alteration is a rare event for ITGA1 at the population level given an average mutation rate of $2.5 \%$, it is the most frequently deleted integrin gene in human cancers (Fig. 2f). Considering the fact that ITGA1, encoding the $\alpha 1$ integrin, is found pervasively downregulated in the majority of human cancers (Fig. 2g), it is conceivable that $\alpha 1$ integrin may play a tumor suppressive role. In support, clinical prognostic analysis unraveled that cancer patients with its higher expression survive longer (Fig. 2h). Contrastively, an upregulation of ITGA1 is also observed in few numbers of cancer types such as kidney renal clear cell carcinoma (KIRC) and glioblastoma multiforme (GBM) (Fig. 2g), indicating again a context-dependent function for individual integrin genes (Table 1 ).

\section{Integrin av $\beta 6$ : a pleiotropic and oncogenic factor}

Among the integrin family, $\alpha v \beta 6$ represents one of the most studied integrins so far, in that (1) it is the only heterodimer that can be formed by the $\beta 6$ subunit [24]; (2) it is barely expressed in healthy adult epithelium, but strongly induced during embryogenesis, tissue repair and tumorigenesis [25]; and (3) it has been found overexpressed in many cancers (e.g., breast [26], gastric [27], prostate [28] and colorectal [29] cancer). Clinically, upregulation of $\alpha v \beta 6$ is closely associated with tumor aggressiveness and serves as an independent unfavorable prognostic indicator $[29,30]$. Mechanistically, it has been reported that, upon serum or EGF stimulation, $\alpha v \beta 6$ binds directly to ERK2 and activates downstream MAPK (as well as other signaling) pathway critical for tumor growth (Fig. 3). Alternatively, integrin facilitates invasiveness through modulating proteolytic activity of ECM via matrix metalloproteinases (MMPs). Induction of $\alpha v \beta 6$ in squamous carcinoma (SCC) increases MMP-9 secretion and subsequent ECM degradation, leading to tumor cell survival and metastasis $[29,31]$. Moreover, studies have demonstrated that $\alpha v \beta 6$ integrin can enhance chemotherapy and radiotherapy resistance. By activating ERK/ MAPK signaling and inhibiting mitochondrial apoptotic pathway, $\alpha v \beta 6$ protects colon cancer cells from 5-FU induced growth inhibition and apoptosis [32]. Additionally, $\alpha v \beta 6$ can also interact with the latent transforming growth factor $\beta$ (TGF $\beta$ ) complexes and subsequently releases the active TGF $\beta$ from the complex, which then binds to its receptor and activate TGF $\beta / S M A D$ pathway [33]. In turn, TGF $\beta$ induces epithelial mesenchymal transition (EMT) process that aids metastasis. In triple negative BCa (TNBC), studies indicated that $\alpha \mathrm{v} \beta 6$ positively regulates expression of SOX4 (a TGF $\beta$ target gene) and the SOX4-driven immune evasion pathway [34]. Preclinically, treating tumors with an $\alpha v \beta 6$ blocking antibody that inhibits activation of TGF $\beta$ and SOX4 expression exhibited reduced invasiveness and, simultaneously, enhanced sensitivity to T-cell mediated immunity [34]. Altogether, these studies establish generally $\alpha v \beta 6$ as an oncogenic, but pleiotropic, factor in distinct tumorigenic contexts (Fig. 3) and as an attractive therapeutic target.

\section{Integrin in control of tumor stemness}

Human cancer is a heterogeneous disease with virtually all tumors containing phenotypically and functionally distinct subsets of cells [49]. Cancer stemness, referring to the stem cell (SC)-like phenotype of cancer cells, has been widely recognized as a vital player in different aspects of tumorigenesis [50,51]. In general, cancer stemness increases along with tumor progression [51]. Among the diverse subsets of cancer cells residing in a tumor, there is a small population of stem-like cancer cells (i.e., cancer stem cells, CSCs) that harbor selfrenewing, differentiation and tumor initiating capability. Mounting evidence has established CSCs as drivers of tumor progression, treatment resistance, disease relapse and metastasis $[49,51]$. Like normal SCs that are typically associated with a particular local niche, the tumor microenvironment (TME) dictates the fate of CSCs by providing cues to direct their biological behavior. Integrin, as the bridge transmitting "outside-in" and "insideout" signals (Fig. 1b), is essential for SCs to sense and respond to diverse cues in both normal and diseased tissues [4]. In support, increasing studies have unraveled that integrins could function as both phenotypic markers and functional regulators of CSCs, opening another layer of complexity of CSC regulation, as well as opportunities to devise integrin-targeted therapeutics to impede cancer stemness $[50,52]$.

\section{Integrins function as CSC markers}

Previously, a number of cell surface markers (e.g., CD44, CD90, CD133) have been extensively characterized to phenotypically mark CSC subpopulations in both cell cultures and clinical samples for many cancer types [51]. Notably, these markers often also mark the normal SCs and lack organ-specificity due to their broad expression repertoire cross tissues, highlighting a need in searching for other markers that can better and more precisely 


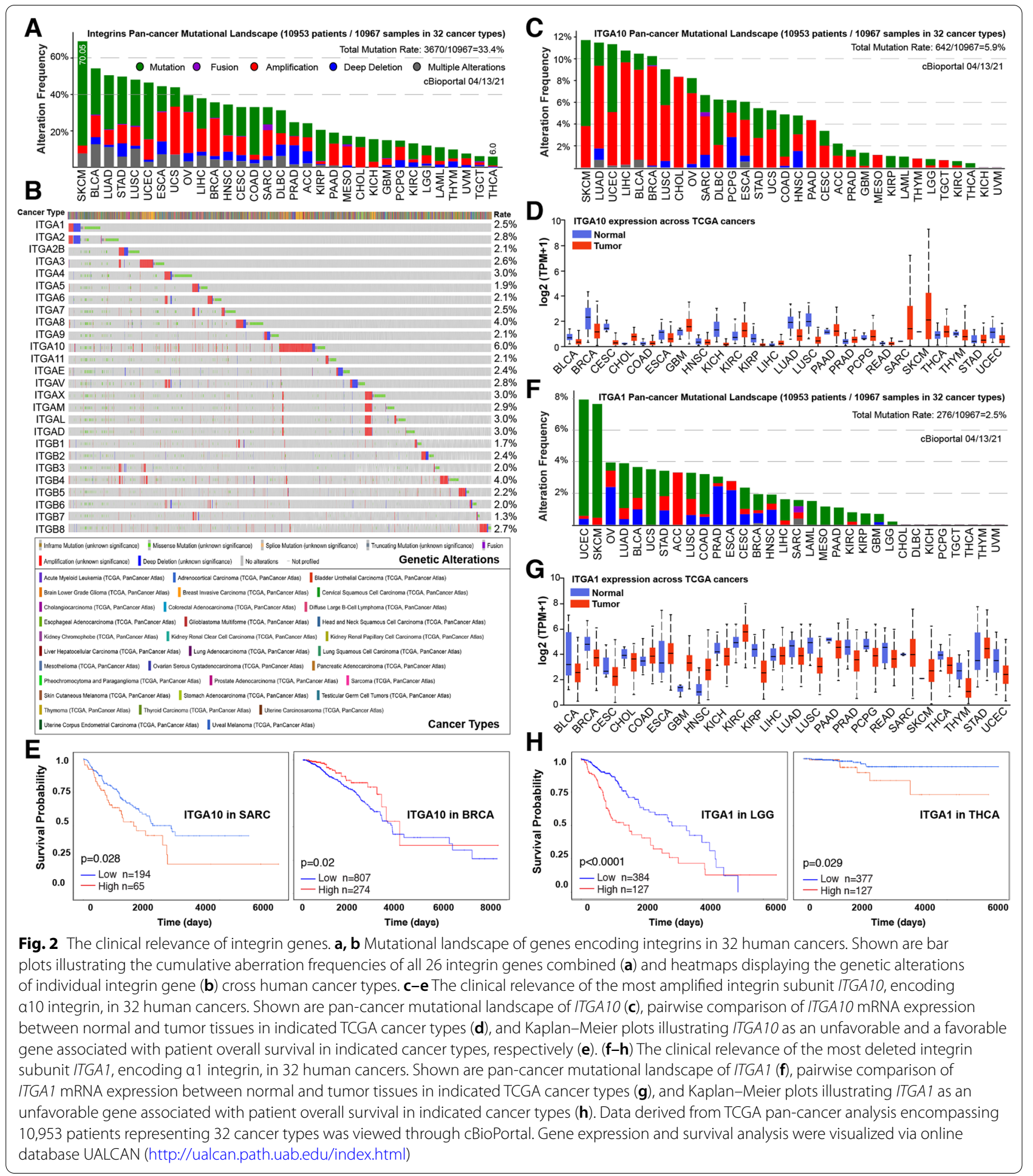

characterize CSCs. In the past decade, another group of transmembrane proteins that have attracted global attention are integrins, owing to their cell surface location and established contributions to tumor evolution [53]. One of the most well-studied integrins reported as SC and CSC markers is $\alpha 6$ (CD49f), a laminin binding receptor. The $\alpha 6$ integrin is highly expressed in embryonic and neural SCs and studies have reported that $\alpha 6^{+}$glioblastoma cells are capable of self-renewal and multi-lineage differentiation, establishing $\alpha 6$ as a CSC marker [54]. Interestingly, 


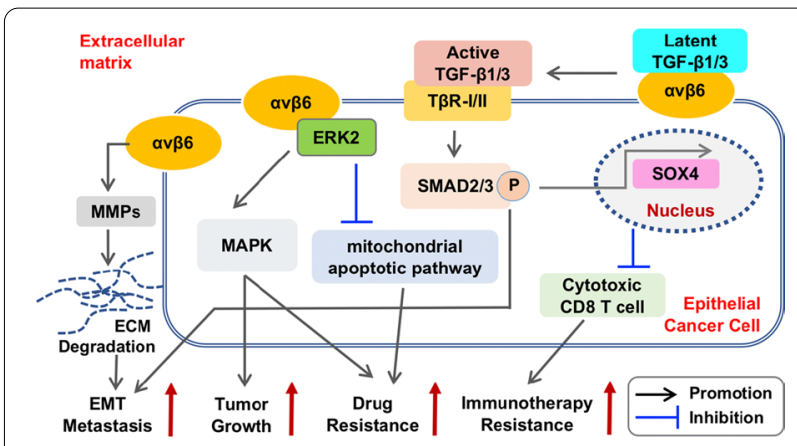

Fig. 3 Integrin av $\beta 6$ signalosome in tumor progression. Studies have suggested multiple pro-tumorigenic roles of av $\beta 6$ integrin involving distinct downstream pathways, in accelerating tumor progression. For example, the av $\beta 6$ integrin can facilitate cancer cell invasiveness and thus metastasis via increasing MMPs secretion and ECM degradation. By interacting with ERK2, av $\beta 6$ activates MAPK signaling to increase cell proliferation and tumor growth, and to inhibit 5-FU-induced cancer cell apoptosis through suppression of the mitochondrial apoptotic pathway (by impairing the cytochrome C release, decreasing the activity of caspase- 3 and caspase-9, and upregulating the anti-apoptotic factor $\mathrm{BCL}-2$ ), leading to drug resistance. Furthermore, the av $\beta 6$ integrin can interact with latent TGF $\beta$ and subsequently activate TGF $\beta$-linked pathways to positively contribute to EMT process and metastasis. Alternatively, the activated TGF $\beta$ signaling drives expression of cancer stemness factors (e.g., SOX4) to evade immunotherapy. Lines with arrows and perpendicular denote a promotion or an inhibition effect, respectively. P within the circle denotes phosphorylation. See text for details

compared to CD133 alone which is not CSC-exclusive as $\mathrm{CD}_{133^{-}}$glioblastoma cells also retains tumor initiation ability, a combination of $\alpha 6$ and CD133 better defines glioblastoma CSCs [54]. Notably, besides glioblastoma, an enrichment of $\alpha 6$ is also observed in a variety of CSCs residing in different tumor types (e.g., breast, prostate, colon) [51], suggesting a broader application. For example, integrin $\alpha 6 \beta 3$ is commonly used as a marker for luminal progenitors in the mouse mammary gland and in their ErbB2-transformed cancerous derivatives [55]. Recently, integrin $\alpha 7$ was identified as a functional CSC marker in oesophageal squamous cell carcinoma (OSCC) [56]. The $\alpha 7^{+}$cells exhibited an enhanced stemness, including self-renewal, differentiation and chemotherapy resistance. Clinically, a high frequency of $\alpha 7^{+}$cells in OSCC tissues is significantly associated with poor differentiation, lymph node metastasis and worse prognosis. Interestingly, $\alpha 7$ is found co-expressed with CD90 (a previously defined CSC marker in OSCC), but not all $\mathrm{CD} 90^{+}$cells are $\alpha 7^{+}$. The $\mathrm{CD} 90^{+} \alpha 7^{+}$double positive cells possessed cardinal CSC properties as $\mathrm{CD} 90^{-} \alpha 7^{-}$ cells barely formed tumors when implanted in vivo, suggesting that $\alpha 7$ can further stratify $\mathrm{CD} 90^{+}$population towards stemness compared to $\mathrm{CD} 90^{+}$alone. Mechanistically, $\alpha 7$ regulates CSC properties through activation of
FAK-mediated signaling pathways [56]. Similarly, there are other integrins that have been suggested to be CSC biomarkers in different solid cancer types (Table 2).

\section{Integrins regulate CSCs in tumor development and progression}

In addition to serve as CSC markers, there is overwhelming evidence that integrins and integrin signalosome play crucial roles in potentiating CSCs function $[2,51]$, and CSCs usually coopt niche-integrin signals to fuel their expansion [4]. Here, by providing cases in point, we highlight the integrin $\beta 1, \alpha 6$ and $\alpha \mathrm{v}$, owing to the fact that they are the most studied ones in regulation of CSCs. Many other integrins that functionally regulate CSCs are also briefly described in Table 2 .

\section{Integrin $\beta 1$}

The $\beta 1$ subunit (CD29) can form dimers with the biggest pool of at least 10 different $\alpha$ chain partners $(\alpha 1-9$ and $\alpha v$ ). It thus has a central role in engaging the TME owing to its ability to bind a broad spectrum of ECM and cell adhesion molecules. In support, studies have reported that an increased level of $\beta 1$ integrin correlates with tumor progression, metastasis and therapy resistance in many cancer types [57]. Molecularly, multiple integrin-dependent and cancer-related pathways (such as FAK, ERK/MAPK, Src, AKT and Ras) are activated as a result of increased $\beta 1$ level, empowering promotion of tumor growth and treatment resistance [4]. Interestingly, it has been reported that squamous cell carcinoma (SCC) contains two highly tumorigenic CSC populations that differ in CD34 levels but are enriched for integrins and coexist at the SCC-stroma interface [58]. CD34 was previously identified as a hair follicle SC marker that can be used to purify a skin CSC-like population [51]. Specifically, the tumor initiation ability of SCC CSCs measured by serial limit-dilution transplantation assays seems to be governed by $\alpha 6 \beta 1$ but not CD34, as only $\alpha 6^{\text {hi }} \beta 1^{\text {hi }}$ populations, regardless of CD34 expression level, can initiate secondary tumors. This suggested that high level of $\beta 1$ integrin is a better defining marker for tumor initiating CSCs in SCCs [58]. Intriguingly, molecular regulation of the interchangeable states between $\alpha 6^{\mathrm{hi}} \beta 1^{\mathrm{hi}} \mathrm{CD} 34^{\mathrm{hi}}$ and $\alpha 6{ }^{\text {hi }} \beta 1^{\text {hi }} \mathrm{CD} 34^{\text {low }}$ is distinct. In one state, activated $\beta 1$ via binding to its ligand fibronectin (FN1) promotes selfrenewal of both $\mathrm{CD} 34^{\text {hi }}$ and CD34 ${ }^{\text {low }}$ CSC populations; whereas in another state, active TGF $\beta / T \beta R I I$ signaling primarily impacted on $\alpha 6^{\text {hi }} \beta 1^{\text {hi }} C D 34^{\text {hi }}$ cells to restrain their stemness and induce differentiation. Unsurprisingly, FAK signaling is important for the tumorigenic properties of both CSC subsets [58]. CSC phenotype is tightly linked to metastasis. There is also evidence indicating a critical role of $\beta 1$ integrin in metastasis, but discrepancy 
exists. On the one hand, the $\beta 1$-dependent adhesion was experimentally essential for cancer cells to contact with the subendothelial matrix and thus $\beta 1$ integrin was necessary for invading through the basement membrane after tumor cells clearing the endothelial wall [12]. Therapeutically, $\beta 1$ inhibition significantly reduces the formation of metastatic foci in several solid tumor types [12]. On the other hand, depletion of $\beta 1$ integrin in TNBC epithelial cells reduced tumor growth, but markedly enhanced lung metastasis [59], suggesting a context-dependent effect of $\beta 1$-targeting therapies.

Besides the cell autonomous activity, integrins can also function in an endocrine manner. Integrin can help cancer cells to build a new beneficial niche by secreting integrin ligands. $\mathrm{BCa}$ cells produce tenascin $\mathrm{C}$, a ligand of $\beta 1$ and $\beta 3$ integrins, to promote self-renewal of CSCs and to potentiate metastasis-initiating ability. Furthermore, integrin $\beta 1$ has been proposed to promote resistance to antiangiogenic therapy through elevation of multiple malignant programs facilitated by interactions with the TME [57]. One such program is the vasculogenic mimicry (VM) formation by cancer cells, in which $\beta 1$ is a critical regulator [60]. Consequently, blocking $\beta 1$ with OS2966, a neutralizing $\beta 1$ monoclonal antibody, attenuates aggressive tumor phenotypes in vitro and inhibits growth of antiangiogenic therapy-resistant tumor xenografts in vivo [57], constituting a potential therapeutic opportunity.

\section{Integrin $a 6$}

As a laminin binding integrin, $\alpha 6$ (CD49f) mainly heterodimerizes with two $\beta$ chains ( $\beta 1$ or $\beta 4$ ) to primarily anchor epithelial cells to laminin in the basement membrane [4]. CD49f has been widely used to mark, and is functionally essential for the maintenance of, CSCs in a number of solid cancer types [51]. Genetic depletion of ITGA6, encoding $\alpha 6$ subunit, suppresses CSCs and their tumor initiation capacity in glioblastoma [61]. Mechanistically, $\alpha 6$ positively regulates the expression of fibroblast growth factor receptor 1 (FGFR1) through a ZEB1/ YAP transcription complex, leading to increased expression of multiple SC factors in cancer cells [61]. In TNBC, CSCs contain both epithelial and mesenchymal subsets and there are two distinct cytoplasmic domains of the $\alpha 6$ integrin ( $\alpha 6 \mathrm{~A}$ and $\alpha 6 \mathrm{~B}$ ) generated by alternative splicing. These two splicing variants drive, interestingly, opposite phenotype: $\alpha 6 \mathrm{~A} \beta 1$ maintains an epithelial phenotype; whereas $\alpha 6 \mathrm{~B} \beta 1$ defines the mesenchymal population and is necessary for CSC function [62]. But in both phenotypes, $\alpha 6$ upregulates expression of a key SC factor, BMI-1, via activation of FAK signaling to contribute to CSCs [63]. In prostate cancer (PCa), miR-25 functions as a tumor suppressor in highly metastatic prostate CSCs

Table2 Integrins function as CSC markers in different solid cancers

\begin{tabular}{|c|c|c|c|}
\hline Integrin subtype & Cancer type & Functions & References \\
\hline \multirow[t]{3}{*}{$\beta 4$} & TNBC & Identifies a CSC-enriched population with partial mesenchymal traits & [78] \\
\hline & PDAC & High level of $\beta 4$ expression significantly correlates with stemness and EMT & {$[79]$} \\
\hline & Prostate & $\begin{array}{l}\text { Sustains the self-renewal of putative CSCs and promotes tumorigenesis by amplifying ErbB2 and } \\
\text { c-Met signaling in tumor progenitor cells }\end{array}$ & {$[80]$} \\
\hline a6 & Glioblastoma & Co-expresses with conventional glioblastoma CSC markers and enriched for CSCs & {$[54]$} \\
\hline a7 & OsCC & $\begin{array}{l}\text { Identifies a CSC-enriched population with elevated expression of SC genes and EMT features. The a7 } \\
\text { co-expresses with the traditional CSC marker CD90 but further stratifies and marks a more tumori- } \\
\text { genic subset }\end{array}$ & {$[56]$} \\
\hline$\beta 3$ & Breast & $\begin{array}{l}\text { A luminal epithelial progenitor marker that identifies a CSC population in mouse models of mammary } \\
\text { tumorigenesis }\end{array}$ & [81] \\
\hline$\beta 8$ & Glioblastoma & $\begin{array}{l}\text { Overexpresses in and maintains glioblastoma CSC, and its overexpression induces radio-resistance } \\
\text { and is correlated with poor prognosis }\end{array}$ & [82] \\
\hline $\operatorname{av} \beta 3$ & Breast & $\begin{array}{l}\text { Regulates adult mammary SCs during pregnancy, and activates Slug in BCa cells to increase CSC } \\
\text { features such as tumorsphere formation and tumor initiation }\end{array}$ & [83] \\
\hline$a 6$ and $\beta 3$ & Breast & $\begin{array}{l}\text { a } 6^{\text {high }} \beta 3^{\text {high }} \text { identifies a CSC-enriched population with enhanced tumorsphere formation and drug } \\
\text { resistance to pacitaxel and doxorubicin in mouse Her2/neu transgenic breast tumors }\end{array}$ & [55] \\
\hline \multirow[t]{2}{*}{$\alpha 2 \beta 1$} & NSCLC & $\begin{array}{l}\text { Exosomes derived from NSCLC cells carrying low levels of miR-34c-3p induce upregulation of a2 } \beta 1 \text {, } \\
\text { which promotes cancer cell invasion and migration }\end{array}$ & [84] \\
\hline & Colon & Enhances metastatic capability and stemness of colorectal cancer cells via PI3K/AKT/Snail axis & {$[85]$} \\
\hline \multirow[t]{2}{*}{$\beta 1$} & HNSCC & Promotes stemness, chemoresistance and tumor-forming capacity of cancer cells & [86] \\
\hline & OSCC & $\begin{array}{l}\text { Overexpresses in stem-like cancer cells and enhances cell proliferation, migration and tumorsphere } \\
\text { formation }\end{array}$ & [87] \\
\hline
\end{tabular}

CSC cancer stem cells, TNBC triple-negative breast cancer, PDAC pancreatic ductal adenocarcinoma, OSCC oral squamous cell carcinoma, NSCLC Non-small-cell lung cancer, HNSCC head and neck squamous cell carcinoma, EMT epithelial-mesenchymal transition 
defined by ALDH ${ }^{\text {hi }}$ phenotype. One of the key targets of miR-25 is $\alpha 6$. Experimentally, overexpression of miR-25 significantly reduces the invasive behavior of $\mathrm{PCa}$ cells in vitro and blocks extravasation and hence metastatic colonization in a zebrafish model in vivo [64].

\section{Integrin av}

The $\alpha v$ integrin forms heterodimers with one of the five different $\beta$ subunits $(\beta 1,3,5,6$ or 8 ) and the $\alpha v$-containing integrins recognize RGD peptide motifs in various ECM ligands $[2,12]$. Studies have linked an aberrant regulation of $\alpha v$ integrins, particularly $\alpha v \beta 3$ and $\alpha v \beta 5$, with poor patient outcome and higher incidence of metastasis for many epithelial cancers $[4,65]$. Functionally, expression of the $\alpha \mathrm{v}$ integrin is reported to be tightly associated with a CSC phenotype, because it is unique in its ability to cluster on the surface of non-adherent tumor cells where it contributes to anchorage-independent growth $[4,66]$. It is well established that anchorage-independent growth is a hallmark of tumor stemness and progression. In support, $\alpha v \beta 3$ was found necessarily and sufficiently to reprogram tumor cells toward a CSC phenotype (including tumor initiation, self-renewal and, particularly, resistance to receptor tyrosine kinase (RTK) inhibitors such as erlotinib) in breast, lung and pancreatic carcinomas [46]. To do so, $\alpha v \beta 3$ interacts with Galectin- 3 independent of its ligand binding domain and then recruits KRAS and RalB to the plasma membrane, leading to activation of NF-kB signaling via TBK1 [46]. Similarly, in gastric cancer, $\alpha v \beta 3$ mediates intercellular adhesion in multicellular aggregates (MCAs) and activates GLI1 through a non-classic ERK1/2 pathway and the classic Hedgehog pathway to maintain CSCs. Importantly, the MCAs were found responsible for peritoneal metastasis [67]. Consequently, $\alpha v \beta 3$ integrin is now established as a CSC marker in multiple solid tumor types [46]. Similarly, $\alpha v \beta 5$ has also been reported to promote stemness-associated invasion and metastasis of tumors growing in preirradiated stroma [68] and brain metastases of lung cancer [69]. The $\alpha v \beta 5$ is recently identified as a CSC marker essential for glioblastoma maintenance and Zika virus (ZIKV) infection [70]. As a neurotropic virus, ZIKV has potentially an oncolytic activity against glioblastoma CSCs characterized by $\alpha v \beta 5$ and SOX 2 expression. Therapeutic inhibition of $\alpha v \beta 5$ by blocking antibodies attenuated ZIKV infection [70]. Furthermore, EMT accelerates stemness and integrin signaling exerts its most evident effect during EMT [4]. The $\beta 8$ heterodimerizes exclusively with the $\alpha v$ to form $\alpha v \beta 8$ integrin, which primarily binds to RGD sequences in ECM-bound latent TGF $\beta 1$ and TGF $\beta 3$ (inactive) protein ligands and mediates subsequent ligand activation and functional TGF $\beta$ signaling. Data mining in TCGA database suggested that $\beta 8$ expression in glioblastoma samples is correlated positively and negatively with the expression of numerous SC/EMT and neural differentiation markers, respectively [71]. Consistently, $\alpha v \beta 8$ integrin is highly expressed in glioblastoma CSCs and essential for their self-renewal and lineage commitment during tumorigenesis. Molecularly, $\alpha \mathrm{v} \beta 8$ promotes tumor development, in part, by driving TGF $\beta 1$-induced DNA replication and CDK1- and CDKN1A/p21 ${ }^{\mathrm{cip}}$-mediated cell cycle progression [72].

All together, these findings reflect that integrins are implicated in nearly every step of cancer progression from primary tumor development to treatment-resistance to metastasis [12]. Strikingly, and in line with the idea that tumor stemness is the main driver of cancer evolution, many integrin-derived signals are frequently reported to be important for CSC functions. Therefore, the integrin control of stemness represents another therapeutic strategy of targeting specific integrins to suppress CSCs via modulation of cell adhesion and integrin/ECM interactions $[4,12,16]$. However, it is worth noting that studies have also shown that integrins can regulate tumor stemness independent of their ECM interaction [4]. Interestingly, this adhesion-independent functions of integrins trigger pathways distinct from the typical signaling cascade and cytoskeletal links (Fig. 1b). In such cases, it is conceivable that integrin antagonists that compete for ligand binding or impair ligand binding ability would fail to produce desirable therapeutic benefits (see below), thus warranting the development of innovative strategies.

\section{Integrins in cancer-derived exosomes aid metastasis}

Metastasis is the leading cause of cancer mortality. The disseminated cancer cells must adapt to colonize and thrive at the "foreign" metastatic site. In recent years, exosomes have been proposed as the "vanguard" to prime distant organs to form pre-metastatic niche [73]. Exosomes are small membrane vesicles $(30-100 \mathrm{~nm}$ in diameter) secreted by cancer cells [74]. By capsuling functional biomolecules (e.g., proteins, lipids, RNA and DNA), exosomes are both short- and long-distance mediators of intercellular communication through modulation of the recipient cells on ligand-receptor interaction and/or cargo release [74]. Integrins are the most abundantly expressed receptors on the surface of exosomes, and given their ECM modulating abilities, exosome-carrying integrins have been recognized to actively participate in metastasis [73]. In PCa, tumor cells secreted $\alpha v \beta 6$ which is not detectable in normal human prostate, and transferred it intercellularly via exosomes to an $\alpha v \beta 6$-negative recipient cell, finally enhancing cell 
migration and metastasis in a paracrine fashion [75]. The castration resistant PCa (CRPC) is currently a lethal variant of aggressive $\mathrm{PCa}$ [49]. Emerging evidence indicated that small extracellular vesicles ( $\mathrm{sEVs}$ ) secreted by $\alpha v \beta 3$-expressing CRPC cells are capable of reprogramming adenocarcinoma cells towards the most aggressive neuroendocrine phenotype, whereas $\alpha v \beta 3$-nonexpressing sEVs have minimal impact on tumor growth [76]. In pancreatic cancer, an array of studies have also identified roles of the exosomal integrins (e.g., $\beta 4, \alpha 6 \beta 4, \alpha v \beta 5$ ) in disease progression and metastasis [73]. Broadly, a comprehensive proteomic survey has portrayed the diverse integrin repertoires in exosomes derived from distinct types of primary tumors [77], indicative a selectivity of exosome cargo packaging. Functionally, these distinct integrin heterodimers determine organotropic metastasis by interacting with resident cells at targeted destination [77]. For instance, exosomal $\alpha 6 \beta 4$ and $\alpha 6 \beta 1$ integrins bind to pro-inflammatory $\mathrm{S} 100 \mathrm{~A} 4^{+}$fibroblasts and $\mathrm{SPC}^{+}$epithelial cells and help target metastatic cells to the lung; whereas $\alpha v \beta 5$ specifically bind to $\mathrm{F} 4 / 80^{+}$ macrophages and is linked to liver metastasis [77]. Collectively, these findings unravel another layer of complexity in integrin-mediated control of tumor progression, especially metastasis.

\section{Integrins as therapeutic targets in cancer}

Integrins modulate mainly cell-cell and cell-ECM interaction, and in certain contexts activate encountered growth factor receptors (GFRs), to amplify the signaling cascade to ultimately alter cell behavior. An association of integrins with specific GFRs can result in their partial activation: $\alpha v \beta 3$ can partner with the receptors of insulin, platelet derived growth factor (PDGF), and vascular endothelial growth factor (VEGF); whereas $\alpha 5 \beta 1$ often associates with the EGF receptor (EGFR) $[4,9]$. Moreover, $\alpha 5 \beta 1$ can also binds to fibronectin to induce ligandindependent activation of the RTK MET; whereas $\alpha 6 \beta 4$ integrin regulates MET oncogenic signaling [12]. Obviously, because of the functional importance and their ligand binding and regulatory sites are extracellular (which render accessibility to diverse therapeutic interventions), integrins are thought idea drug targets [12]. Notably, intensive pre-clinical studies have linked an altered expression or functionality of integrins to human tumorigenesis, directly leading to a focus on development of agents targeting integrins over the past decades [88]. In the non-cancer treatment field, there are successful anti-integrin drugs on the market. The $\beta 3$ blocking antibody, Abciximab, has been used to prevent clot formation during high-risk coronary angioplasty [89]. Natalizumab, a pan- $\alpha 4$ inhibitory antibody, is now wildly used to treat multiple sclerosis (MS) and Crohn's disease. It is uniquely efficacious in MS, although a side-effect of developing fetal progressive multifocal leukoencephalopathy was observed [90]. Natalizumab has been proven by the US Food and Drug Administration to treat patients under rigorous monitoring for John Cunningham polyoma virus [90]. In the setting of cancer management, although translating the basic research findings into clinic is challenging, efforts are been made towards development of effective integrin-blocking therapeutics for treating deadly cancers.

\section{Targeting integrins by monoclonal antibodies}

Five out of the nine integrin-targeting drugs made to the clinical trial stages are anti-integrin $\alpha v$ (Table 3). Notably, the $\alpha \mathrm{v}$ subunit is usually not expressed in epithelial cells and is hence largely nonessential for development (justifying $\alpha v$ as a desirable target), but has been implicated in tumor angiogenesis and metastasis [16]. Experimental blocking of $\alpha \mathrm{v}$-containing integrins' ligand binding function inhibits endothelial cell-mediated angiogenesis, accompanied with reduced tumor cell proliferation, migration, and metastasis [16]. These findings greatly stimulate the efforts of developing $\alpha v$ antagonists for clinical use. Intetumumab (CNTO 95), a fully human monoclonal antibody, recognizes the $\alpha \mathrm{v}$ integrins with demonstrated blocking activity against $\alpha v \beta 3$ and $\alpha v \beta 5$ [91]. In $\mathrm{BCa}$, intetumumab treatment interrupts integrin $\alpha v$-activated pathways associated with focal adhesions and cell motility, thus leading to reduced tumor growth and lung metastasis in mouse models [91]. In a phase I clinical trial, CNTO 95 was safely tolerated in patients with malignant solid tumors [92]. However, results from a phase II trial in melanoma demonstrated no statistically significant efficacy for, although there seemed a trend of, an improved overall survival with CNTO 95 treatment alone or combined with dacarbazine (a chemotherapy) [93].

Abituzumab (EMD 525797), a fully human de-immunized monoclonal antibody that targets all five $\alpha v$ integrins, is de-glycosylated and expected to not cause antibody dependent cellular cytotoxicity (ADCC) [2]. In a large phase II trial in CRPC with 60 patients in each arm, abituzumab was evaluated in combination with hormone agonist/antagonist therapy in chemotherapy naïve patients with progressive bone lesions. Results showed that although the incidence of bone lesion progression was decreased, but the extended progression free survival (PFS) was not improved between the treated and placebo groups [94], suggesting a limited clinical efficacy. Abituzumab has also been examined in metastatic colorectal cancer (mCRC) in a phase I/II trial. A favorable safety 
profile was observed in combination with standard of care (EGFR inhibitor cetuximab plus chemotherapy irinotecan) for $\mathrm{mCRC}$, but the primary end point (i.e., PFS) was not met [95]. A biomarker analysis investigating the correlation between integrin expression and treatment outcome suggested that some mCRC patients with a high $\alpha v \beta 6$ expression did benefit from abituzumab-based therapy [95], indicating a need of up-front stratification based on $\alpha v \beta 6$ levels for better clinical practice.

LM609, a functional blocking monoclonal antibody of integrin $\alpha v \beta 3$, has demonstrated anti-angiogenic activity in preclinical animal studies [96]. In a phase I trial, etaracizumab, a humanized version of LM609 (also named Vitaxin commercially) directly against conformational epitope of $\alpha v \beta 3$ integrin, exhibited anti-tumor activity, but seemingly in a manner independent of its antiangiogenic effects, in human melanoma [97]. In a randomized multicenter phase II study of etaracizumab in patients with stage IV melanoma, etaracizumab, as a single agent or combined with dacarbazine (a chemotherapy), displayed acceptable safety profile but did not prolong the survival comparing to dacarbazine alone [98].

Besides the $\alpha v$ integrins, therapeutic targeting of $\beta 1$ integrin has also shown promising efficacy in reducing tumor burden in pre-clinical models. Volociximab, an $\alpha 5 \beta 1$-inhibiting antibody, is reported to block angiogenesis and hence tumor growth in multiple xenograft models [99], but its further development was silenced due to a lack of efficacy in a phase II trial for human solid tumors [100, 101]. A brief description of abovementioned integrin-blocking antibodies that have reached late-stage clinic trials are summarized in Table 3. More information can be obtained in recently published reviews $[4,12,16]$.

\section{Targeting integrins by small molecule inhibitors}

The antibody-based therapies have been, unfortunately and largely, disappointing so far. Although there are few small molecule integrin inhibitors that have reached clinical trial stages, considering the distinct intrinsic properties associated with small molecule versus (vs.) antibody in many aspects, small molecule inhibitors (including short peptides) may offer a new avenue to target integrins. The RGD peptide mimetic, cilengitide, that specifically inhibits both $\alpha v \beta 3$ and $\alpha v \beta 5$ integrins, is the first anti-integrin drug in cancer that has reached the level of phase III trial. Cilengitide has been tested in PCa, SCC of the head and neck and non-small cell lung carcinoma (NSCLC) in phase II trials and glioblastoma (a highly vascularized tumor type) in a phase III trial. It is worth noting that $\alpha \mathrm{v} \beta 3$ expresses highly on angiogenic blood vessels and their ligand vitronectin is reciprocally and abundantly expressed in high grade glioblastoma. Although in preclinical studies cilengitide effectively impaired the angiogenesis and tumor growth [102], it failed to show a desirable anti-tumor efficacy in patients with recurrent glioblastoma in a phase II trial [103]. Moreover, in a phase III trial, cilengitide was assessed in combination with chemoradiotherapy (temozolomide) in patients bearing newly diagnosed glioblastoma with methylated O-6-methylguanine-DNA methyltransferase (MGMT) promoter (a prognostic biomarker for glioblastoma). Unfortunately, no clear positive outcome was observed and thus cilengitide was discontinued for further development [104]. Another antiangiogenic small peptide ATN-161 (a 5aa peptide Ac-PHSCN-NH2 derived from the synergy region of fibronectin) has also been previously evaluated in a phase I trial in patients with solid tumors [105]. ATN-161 binds exclusively to integrin $\beta$ chains and inhibits the function of several integrins implicated in tumor angiogenesis and metastasis. Although it was well tolerated at all dose levels, no objective responses were observed (Table 3) [105].

E-7820 is a sulphonamide-based small molecule. It was used to suppress $\alpha 2$ integrin and thus angiogenesis and solid tumor growth in a panel of xenograft models (e.g., colon, breast, pancreas, and kidney) [106]. Unfortunately, E-7820 showed little efficacy towards advanced CRC in a phase II trial combined with cetuximab (an EGFR targeted agent) [107]. Additionally, early phase I trials can be found for another two small chemical inhibitors, GLPG0187 (a broad spectrum integrin receptor antagonist) [108] and MK0429 (an orally active $\alpha v \beta 3$ integrin inhibitor) [109]. Both drugs were well tolerated, but the therapeutic efficacy was dismal (Table 3).

Furthermore, several natural product compounds are reported to exhibit promising effects in modulating integrin signaling and are thus under investigation towards clinical use. For example, the water extract of Gleditsia sinensis thorns (GST, a traditional medicine used for carbuncles and skin diseases) can suppress the expression of $\alpha 2$ integrin and attenuates migration and adhesion of PCa cells to collagen [110]. D-pinitol, a 3-methoxy analogue of d-chiro-inositol previously identified as an active principle in soy foods and legumes, can reduce the cell surface expression of integrin $\alpha v \beta 3$ through reducing FAK phosphorylation, c-Src kinase activity and NF-kB activation, which in turn negatively regulates $\mathrm{PCa}$ metastasis [111]. These results establish D-pinitol as a novel anti-metastasis agent worthy further exploration. Curcumin, a bioactive lipophilic polyphenol extracted from the rhizome Curcuma longa, has been demonstrated to have a wide pharmacological effects (such as anti-inflammatory, anti-oxidation and anti-tumor activities) [112]. Inspired by its anti-cancer effect against a spectrum of cancer cells accompanied with limited toxicity, curcumin has entered the clinical trial phase and is currently tested 


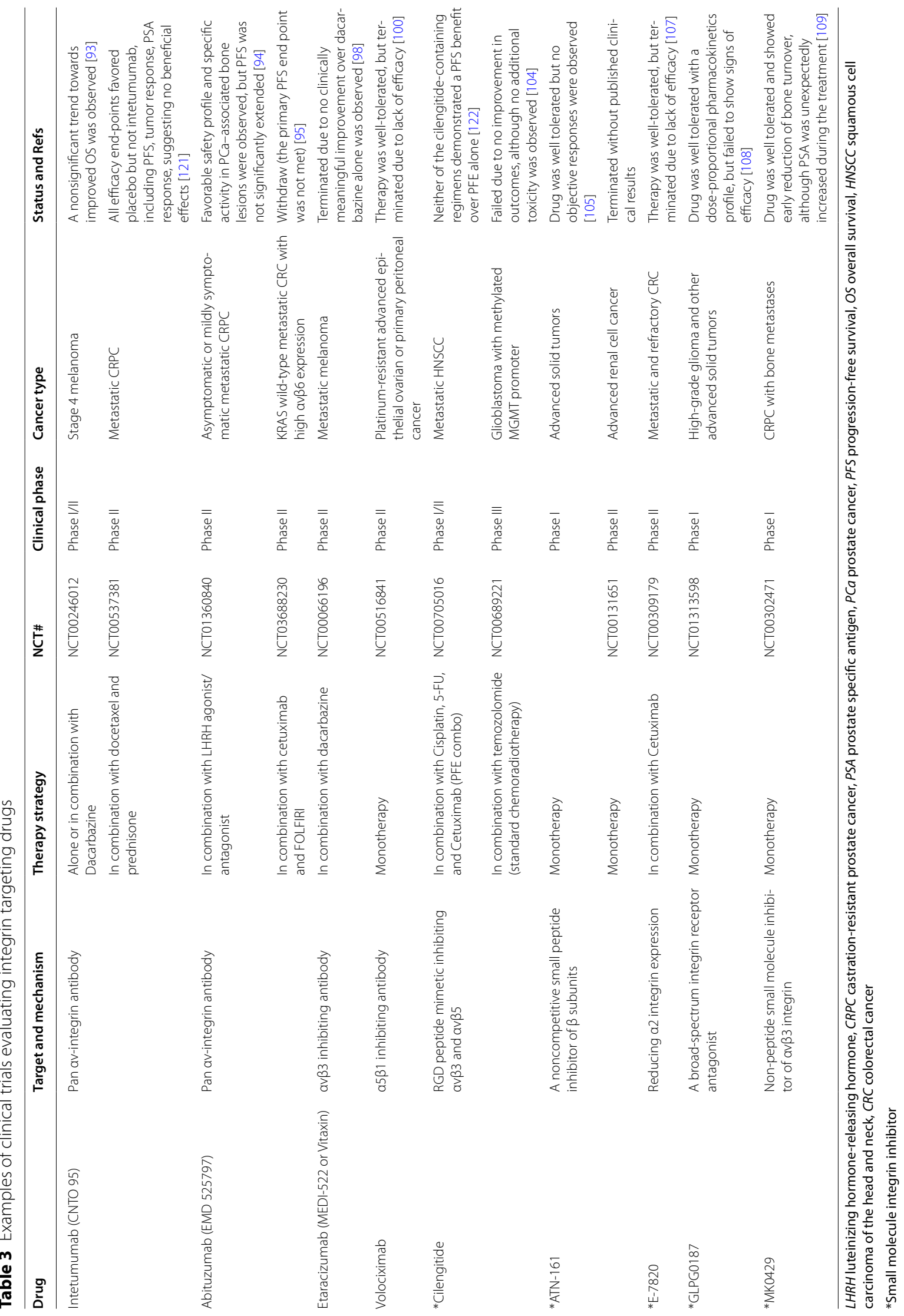


either alone or in combination with other drugs in multiple cancer types [113]. Mechanistically, curcumin was reported to regulate distinct integrins in different cancer types. It blocks $\mathrm{BCa}$ cell motility and invasion by directly disrupting the $\alpha 6 \beta 4$ function, leading to reduction of Akt and ENPP2 (a migration promoting factor) activity. In addition, curcumin also attenuates RCP (Rab coupling protein)-induced ovarian cancer cell invasion by blocking stabilization of $\beta 1$ integrin and consequently inhibiting FAK and EGFR activation [114]. Ouabain, a plant-derived cardioactive glycoside from the seeds of Strophanthus gratus and also recognized as a hormone inhibiting $\mathrm{Na}^{+} /$ $\mathrm{K}^{+}$-ATPase, has been shown to decrease the expression of multiple integrins $(\alpha 4, \alpha 5, \alpha \mathrm{v}$, and $\beta 3$, but not $\beta 1$ and $\beta 4$ ) in human lung cancer cells when treated with nontoxic concentrations, leading to suppression of migration [16]. In addition, there are other compounds currently under investigation [16]. Collectively, some of these natural products have yield promising results in preclinical studies, warranting further therapeutic exploration.

\section{Integrins as probes for cancer imaging and drug delivery}

In addition to a usage as drugs, integrin antagonists with high safety can be repurposed to be integrin tracers in cancer imaging and drug delivery [12]. Different radionuclides labeled RGD peptide antagonists of $\alpha \mathrm{v}$-containing integrins have been developed to provide a non-invasive quantitative assessment of certain integrin expression with positron emission tomography (PET, using positron emitting radionuclides such as ${ }^{18} \mathrm{~F}$ or ${ }^{68} \mathrm{Ga}$ ) or with single photon emission computed tomography (SPECT, using gamma emitters like ${ }^{99 \mathrm{~m}} \mathrm{Tc}$ ) scanning $[115,116]$. This RGD-based optical imaging probes have been used for patient stratification for antiangiogenic therapies, as well as for monitoring treatment response. For example, 18F-fluciclatide is an RGD sequence based cyclic tripeptide and binds to both endothelial-specific $\alpha v \beta 3$ and $\alpha v \beta 5$ with high affinity. This compound has shown successful tumor-recognizing ability in various solid tumor models, and has thus been invested as a radiotracer for imaging of tumor angiogenesis in multiple clinic trails [116]. In a recent trial, ${ }^{18} \mathrm{~F}$-fluciclatide PET imaging was tested to assess antiangiogenic effect of pazopanib (an RTK inhibitor) in patients with platinum-resistant/ refractory ovarian cancer. Administration of pazopanib resulted in a reduction in ${ }^{18} \mathrm{~F}$-fluciclatide baseline uptake, predictive of a good clinical outcome [117]. Similarly, ${ }^{68} \mathrm{Ga}$-NOTA-RGD PET is an RGD containing cyclic peptide c (RGDyK) coupled with SCN-Bz-NOTA and has been evaluated in six patients with hepatic metastases of CRC before antiangiogenic combination therapy with FOLFOX and bevacizumab (VEGF inhibitor). Half of the patients with elevated uptake of ${ }^{68} \mathrm{Ga}$-NOTA-RGD showed a partial response to the treatment; whereas the other half had stable or progressive disease $[116,118]$.

Alternatively, besides applications in monitoring both prognosis and treatment efficacy, the tumor-homing properties of RGD peptides can also be utilized to deliver therapeutically active compounds. Studies have shown that integrin $\alpha v \beta 3$-targeted nanoparticles, through biding to RGD, selectively delivered doxorubicin to tumor vasculature and resulted in a 15-fold improvement in antitumor and anti-metastatic activity of doxorubicin, while largely eliminating the systemic toxicity such as weight loss associated with doxorubicin [119]. Recently, a report using nanoparticulate delivery of short interfering RNAs (siRNA) targeting $\beta 1$ and $\alpha v$ integrin subunits has demonstrated the effectiveness of this strategy in retarding tumor progression in a hepatocellular carcinoma (HCC) mouse model in vivo [120].

\section{Conclusions and perspectives}

Integrin and integrin signalosome are implicated in every step of tumorigenesis from primary tumor development to metastasis [12]. Among these implications, cancer stemness and drug resistance are cordially triggered by alterations in integrin expression and function. Various mechanisms deregulate integrin signaling in cancer [4]. Although multiple clinical trials of anti-integrins in several solid cancers have so far yielded disappointing results which cause a discontinuation in these drugs, this therapeutic barrier of current regimens pose both opportunities as well as needs for developing better integrin blockers [66]. A number of reasons are proposed to be underlying the failure of integrin-inhibiting blockers in clinical practice $[4,66]$. First, xenograft models are often used in pre-clinical studies, and it is now well-accepted that translatability of such cell-line-derived tumor models to actual situations in clinic is limited. This could be one of the major contributing factors to the lack of reproducibility of preclinical findings. Second, the functional redundancy between integrins, exemplified by the fact that one $\alpha$ integrin can partner with multiple $\beta$ subunits and different integrin dimers might possess similar functions, creates difficulty in inhibiting integrin-induced adhesion and signaling with a single agent [4]. Also, this could elicit certain side-effects, although integrin-targeting therapies are generally well-tolerated [88]. Third, and notably, current therapeutic strategies aim predominantly to interfere with integrin-ligand interactions, but an oncogenic integrin-downstream signaling can still occur in a ligand-independent manner. In such scenario, targeting both integrin-mediated adhesion and its downstream signaling might be a better approach. Forth, many clinical trials are executed on a mix population and thus it is difficult to pinpoint why certain number of patients 
response well while the others not. Stratification of cancer patients based on the predictive biomarkers represents a new and practical direction towards a better use of existing drugs.

Thinking differently, there is an emerging and attractive concept of targeting aggressive cancer via combination of integrin-targeted therapy with immunotherapy. Although evidence from clinical trials currently lacks, lines of preclinical studies have established the validity of this novel approach. As a proof-of-concept, combining PD-L1 based immunotherapy with integrin $\alpha v \beta 3$-targeted radionuclide therapy (TRT, ${ }^{177} \mathrm{Lu}-\mathrm{EB}-\mathrm{RGD}$ ) significantly improved the anti-tumor efficacy and overall survival compared with either treatment alone in a murine MC38 colon cancer model [123]. Besides the traditional antibody- or small molecule-based strategies, integrin itself presents as an effective target for cancer immunotherapies. For example, integrin $\beta 4$ is recently suggested to be an immuno-target in mouse models of mammary and head and neck tumors [124]. Using ITGB4 protein-pulsed dendritic cells (ITGB4-DC) for vaccination or adoptive transfer of anti-CD3/anti-ITGB4 bispecific antibody (ITGB4 BiAb)-armed tumor-draining lymph node $\mathrm{T}$ cells, both immunologic strategies significantly inhibited local tumor growth and metastases in both solid tumor models via preferential killing of $\mathrm{ALDH}^{\text {high }} \mathrm{CSCs}$ over non-CSCs. Interestingly, the therapeutic efficacy of both of these ITGB4-targeted immunotherapies was significantly enhanced by the co-administration of anti-PD-L1 without obvious systemic toxicity [124]. Alternatively, studies have explored the possibility of RGD-binding integrins as targets for antibody Fc effector functions in the context of cancer immunotherapy. Using an integrin-binding peptide fused to the antibody Fc-domain (2.5F-Fc), combined with an engineered mouse serum albumin/IL-2 fusion, various types of tumor mouse models were treated and an improved survival was observed [125]. Specifically, this treatment strategy accelerated the activation of $\mathrm{CD}^{+} \mathrm{T}$ cells and natural killer cells by boosting the host immune system, rather than blocking the integrin function, to achieve therapeutic effects. Addition of anti-PD1 therapy to this combination further improved therapeutic responses and predominantly resulted in cures [125]. The chimeric antigen receptors (CAR)-engineered $\mathrm{T}$ cells represent a unique and promising cancer immunotherapy [51]. By utilizing a multiple myeloma (MM)-specific mAb (MMG49) specifically recognizing the activated conformation of integrin $\beta 7$, CAR T cells transduced with MMG49 recognize and preferentially kill MM cells without damaging normal hematopoietic cells in vivo [126]. Considering the upregulation and constitutive activation of many integrins in cancers, the active conformer of certain integrins may present as actionable immunotherapeutic targets.

Although the successful clinical trials based on current methodologies are regrettably few in number, a continued drive to better understand the roles of integrins in tumorigenesis could lead to development of more innovative targeting approaches and a revival in the field $[4,12]$. Elimination of CSCs has been a focus, although challenging, in cancer treatment field. Given that integrin repertoire phenotypically identifies, and functionally operates in, CSCs across multiple tumor types, further delineation of the core mechanisms by which integrin signalosome maintains a CSC phenotype could facilitate designing better drugs and developing multi-modal therapies that integrate both conventional or immunological and CSC therapeutic approaches.

\section{Abbreviations}

ECM: Extra cellular matrix; CSC: Cancer stem cell; TM: Trans-membrane; RGD: Arg-Gly-Asp; VCAM-1: Vascular cell adhesion molecule-1; ICAM-1: IntercelIular adhesion molecule-1; MIDAS: Metal ion-dependent adhesion site; PSI domain: Plexin sempahorin integrin domain; EGF: Epidermal growth factor; TMD: Trans-membrane helical domain; PTB domain: Phosphotyrosine binding domain; FAK: Focal adhesion kinase; SFK: Src family kinase; GRB2: Growth factor receptor bound protein 2; ERK: Extracellular signal regulated kinase; MAPK: Mitogen activated protein kinase; PI3K: Pphosphoinositide 3-OH kinase; LAD-1: Leucocyte adhesion deficiency type 1; CTC: Circulating tumor cell; BCa: Breast cancer; TCGA: The cancer genome atlas; THCA: Thyroid carcinoma; SKCM: Skin cutaneous melanoma; OV: Ovarian serous cystadenocarcinoma; UCS: Uterine carcinosarcoma; BRCA: Breast invasive carcinoma; SARC: Sarcoma; CHOL: Cholangiocarcinoma; LUAD: Lung adenocarcinoma; BLCA: Bladder urothelial carcinoma; LUSC: Lung squamous cell carcinoma; KIRC: Kidney renal clear cell carcinoma; GBM: Glioblastoma multiforme; SCC: Squamous cell carcinoma; MMP: Matrix metalloproteinase; TGF $\beta$ : Transforming growth factor $\beta$; SMAD: Drosophila mothers against decapentaplegic homolog; EMT: Epithelial mesenchymal transition; TNBC: Triple negative breast cancer; SC: Stem cell; TME: Tumor microenvironment; OSCC: Oral squamous cell carcinoma; FN: Fibronectin; FGFR1: Fibroblast growth factor receptor; PCa: Prostate cancer; RTK: Receptor tyrosine kinase; MCAs: Multi cellular aggregates; ZIKV: Zika virus; CRPC: Castration resistance prostate cancer; sEV: Small extracellular vesicle; GFR: Growth factor receptor; PDGF: Platelet derived growth factor; VEGF: Vascular endothelial growth factor; EGFR: Epidermal growth factor receptor; VM: Vasculogenic mimicry; MS: Multiple sclerosis; ADCC: Antibody dependent cellular cytotoxicity; PFS: Progression free survival; mCRC: Metastatic colorectal cancer; NSCLC: Non-small cell lung carcinoma; MGMT: Methylated O-6-methylguanine-DNA methyltransferase; GST: Gleditsia sinensis Thorns; RCP: Rab coupling protein; PET: Positron emission tomography; SPECT: Single photon emission computed tomography; siRNA: Small interfering RNA; HCC: Hepatocellular carcinoma; TRT: Targeted radionuclide therapy; CAR: Chimeric antigen receptors; MM: Multiple myeloma.

\section{Acknowledgements \\ None.}

\section{Authors' contributions}

$J X, Z Z, B X$ and DZ conceived the conceptualization, scope, and outline of this review. JX, CZ, LY, KW and DZ collected and analyzed the relevant references. JX, CZ, MC, BX, ZZ and DZ prepared the schematic illustrations. JX, ZZ and DZ wrote and revised the manuscript. All authors participated in critical reading and the final approval of the manuscript.

\section{Funding}

This work was supported by Grants from the National Natural Science Foundation of China (81972418, DZ), the Wuhan Frontier Science and Technology 
Program (2019020701011490, DZ), the Excellent Youth Foundation of Hunan Province (2021JJ10028, DZ), and the Fundamental Research Funds for the Central Universities (531119200130, DZ).

\section{Availability of data and materials}

The material supporting the conclusion of this review has been included within the article.

\section{Declarations}

\section{Ethics approval and consent to participate}

Not applicable.

\section{Consent for publication}

Not applicable.

\section{Competing interests}

The authors declare that there is no conflict of interests.

\begin{abstract}
Author details
${ }^{1}$ School of Biomedical Sciences, Hunan University, Changsha 410082, Hunan Province, China. ${ }^{2}$ College of Biology, Hunan University, Changsha 410082 , Hunan Province, China. ${ }^{3}$ Department of Urology, School of Medicine, Affiliated Zhongda Hospital of Southeast University, Nanjing 210009, Jiangsu Province, China. ${ }^{4}$ College of Life Science and Technology, Huazhong Agricultural University, Wuhan 430070, Hubei Province, China.
\end{abstract}

Received: 19 July 2021 Accepted: 14 October 2021

Published online: 29 October 2021

\section{References}

1. Hynes RO. Integrins: bidirectional, allosteric signaling machines. Cell. 2002;110(6):673-87.

2. Su CY, Li JQ, Zhang LL, Wang H, Wang FH, Tao YW, Wang YQ, Guo QR, Li JJ, Liu Y, Yan YY, Zhang JY. The biological functions and clinical applications of integrins in cancers. Front Pharmacol. 2020;11:579068.

3. Humphries JD, Byron A, Humphries MJ. Integrin ligands at a glance. J Cell Sci. 2006;119(Pt 19):3901-3.

4. Cooper J, Giancotti FG. Integrin signaling in cancer: mechanotransduction, stemness, epithelial plasticity, and therapeutic resistance. Cancer Cell. 2019;35(3):347-67.

5. Larson RS, Corbi AL, Berman L, Springer T. Primary structure of the leukocyte function-associated molecule-1 alpha subunit: an integrin with an embedded domain defining a protein superfamily. J Cell Biol. 1989;108(2):703-12.

6. Calderwood DA, Tuckwell DS, Eble J, Kühn K, Humphries MJ. The integrin alpha1 A-domain is a ligand binding site for collagens and laminin. J Biol Chem. 1997;272(19):12311-7.

7. Humphries MJ, Symonds EJ, Mould AP. Mapping functional residues onto integrin crystal structures. Curr Opin Struct Biol. 2003;13(2):236-43.

8. Kadry YA, Calderwood DA. Chapter 22: structural and signaling functions of integrins. Biochim Biophys Acta Biomembr. 2020;1862(5):183206.

9. Michael M, Parsons M. New perspectives on integrin-dependent adhesions. Curr Opin Cell Biol. 2020;63:31-7.

10. Kim C, Ye F, Ginsberg MH. Regulation of integrin activation. Annu Rev Cell Dev Biol. 2011;27:321-45.

11. Sun Z, Costell M, Fässler R. Integrin activation by talin, kindlin and mechanical forces. Nat Cell Biol. 2019;21(1):25-31.

12. Hamidi H, Ivaska J. Every step of the way: integrins in cancer progression and metastasis. Nat Rev Cancer. 2018;18(9):533-48.

13. Mainiero F, Murgia C, Wary KK, Curatola AM, Pepe A, Blumemberg M, Westwick JK, Der CJ, Giancotti FG. The coupling of alpha6beta4 integrin to Ras-MAP kinase pathways mediated by Shc controls keratinocyte proliferation. Embo j. 1997;16(9):2365-75.

14. Shaw LM, Rabinovitz I, Wang HH, Toker A, Mercurio AM. Activation of phosphoinositide 3-OH kinase by the alpha6beta4 integrin promotes carcinoma invasion. Cell. 1997:91(7):949-60.
15. Raftopoulou M, Hall A. Cell migration: Rho GTPases lead the way. Dev Biol. 2004;265(1):23-32.

16. Aksorn N, Chanvorachote P. Integrin as a molecular target for anticancer approaches in lung cancer. Anticancer Res. 2019;39(2):541-8.

17. Wehrle-Haller B, Imhof BA. Integrin-dependent pathologies. J Pathol. 2003;200(4):481-7.

18. Hogg N, Bates PA. Genetic analysis of integrin function in man: LAD-1 and other syndromes. Matrix Biol. 2000;19(3):211-22.

19. Reynolds LE, Wyder L, Lively JC, Taverna D, Robinson SD, Huang X, Sheppard D, Hynes RO, Hodivala-Dilke KM. Enhanced pathological angiogenesis in mice lacking beta3 integrin or beta3 and beta5 integrins. Nat Med. 2002;8(1):27-34.

20. Guo W, Giancotti FG. Integrin signalling during tumour progression. Nat Rev Mol Cell Biol. 2004;5(10):816-26.

21. Cagnet S, Faraldo MM, Kreft M, Sonnenberg A, Raymond K, Glukhova MA. Signaling events mediated by a3 $\beta 1$ integrin are essential for mammary tumorigenesis. Oncogene. 2013;33(34):4286-95.

22. Ramirez NE, Zhang Z, Madamanchi A, Boyd KL, O'Rear LD, Nashabi A, Li Z, Dupont WD, Zijlstra A, Zutter MM. The alpha(2)beta(1) integrin is a metastasis suppressor in mouse models and human cancer. J Clin Invest. 2011;121(1):226-37.

23. Gao J, Aksoy BA, Dogrusoz U, Dresdner G, Gross B, Sumer SO, Sun Y, Jacobsen A, Sinha R, Larsson E, Cerami E, Sander C, Schultz N. Integrative analysis of complex cancer genomics and clinical profiles using the cBioPortal. Sci Signal. 2013;6(269):11.

24. Niu J, Li Z. The roles of integrin alphavbeta6 in cancer. Cancer Lett. 2017:403:128-37.

25. Breuss JM, Gallo J, DeLisser HM, Klimanskaya IV, Folkesson HG, Pittet JF, Nishimura SL, Aldape K, Landers DV, Carpenter W, et al. Expression of the beta 6 integrin subunit in development, neoplasia and tissue repair suggests a role in epithelial remodeling. J Cell Sci. 1995;108(Pt 6):2241-51

26. Katoh D, Nagaharu K, Shimojo N, Hanamura N, Yamashita M, Kozuka Y, Imanaka-Yoshida K, Yoshida T. Binding of av $\beta 1$ and av $\beta 6$ integrins to tenascin- $C$ induces epithelial-mesenchymal transition-like change of breast cancer cells. Oncogenesis. 2013;2(8):65.

27. Kawashima A, Tsugawa S, Boku A, Kobayashi M, Minamoto T, Nakanishi I, Oda Y. Expression of alphav integrin family in gastric carcinomas: increased alphavbeta6 is associated with lymph node metastasis. Pathol Res Pract. 2003;199(2):57-64.

28. Lu H, Wang T, Li J, Fedele C, Liu Q, Zhang J, Jiang Z, Jain D, lozzo RV, Violette SM, Weinreb PH, Davis RJ, Gioeli D, FitzGerald TJ, Altieri DC, Languino LR. alphavbeta6 integrin promotes castrate-resistant prostate cancer through JNK1-mediated activation of androgen receptor. Cancer Res. 2016;76(17):5163-74.

29. Bates RC, Bellovin DI, Brown C, Maynard E, Wu B, Kawakatsu H, Sheppard D, Oettgen P, Mercurio AM. Transcriptional activation of integrin beta6 during the epithelial-mesenchymal transition defines a novel prognostic indicator of aggressive colon carcinoma. J Clin Invest. 2005;115(2):339-47.

30. Zhang ZY, Xu KS, Wang JS, Yang GY, Wang W, Wang JY, Niu WB, Liu EY, Mi YT, Niu J. Integrin alphanvbeta6 acts as a prognostic indicator in gastric carcinoma. Clin Oncol (R Coll Radiol). 2008;20(1):61-6.

31. Thomas GJ, Lewis MP, Hart IR, Marshall JF, Speight PM. AlphaVbeta6 integrin promotes invasion of squamous carcinoma cells through up-regulation of matrix metalloproteinase-9. Int J Cancer. 2001;92(5):641-50.

32. Liu S, Wang J, Niu W, Liu E, Wang J, Peng C, Lin P, Wang B, Khan AQ, Gao H, Liang B, Shahbaz M, Niu J. The beta6-integrin-ERK/MAP kinase pathway contributes to chemo resistance in colon cancer. Cancer Lett. 2013;328(2):325-34.

33. Margadant C, Sonnenberg A. Integrin-TGF-beta crosstalk in fibrosis, cancer and wound healing. EMBO Rep. 2010;11(2):97-105.

34. Bagati A, Kumar S, Jiang P, Pyrdol J, Zou AE, Godicelj A, Mathewson ND, Cartwright ANR, Cejas P, Brown M, Giobbie-Hurder A, Dillon D, Agudo J, Mittendorf EA, Liu XS, Wucherpfennig KW. Integrin alphavbeta6-TGFbeta-SOX4 pathway drives immune evasion in triple-negative breast cancer. Cancer Cell. 2021;39(1):54-67e59.

35. Kanda R, Kawahara A, Watari K, Murakami Y, Sonoda K, Maeda M, Fujita $H$, Kage M, Uramoto $H$, Costa C, Kuwano M, Ono M. Erlotinib resistance 
in lung cancer cells mediated by integrin $\beta 1 /$ Src/Akt-driven bypass signaling. Cancer Res. 2013;73(20):6243-53.

36. Sottnik JL, Daignault-Newton S, Zhang X, Morrissey C, Hussain MH, Keller ET, Hall CL. Integrin alpha2beta 1 (a2 $\beta 1$ ) promotes prostate cancer skeletal metastasis. Clin Exp Metastasis. 2013;30(5):569-78.

37. Bartolomé RA, Barderas R, Torres S, Fernandez-Aceñero MJ, Mendes M, García-Foncillas J, Lopez-Lucendo M, Casal Jl. Cadherin-17 interacts with a2 $\beta 1$ integrin to regulate cell proliferation and adhesion in colorectal cancer cells causing liver metastasis. Oncogene. 2014;33(13):1658-69.

38. Varzavand A, Hacker W, Ma D, Gibson-Corley K, Hawayek M, Tayh OJ, Brown JA, Henry MD, Stipp CS. alpha3beta1 integrin suppresses prostate cancer metastasis via regulation of the hippo pathway. Cancer Res. 2016;76(22):6577-87.

39. Hu T, Zhou R, Zhao Y, Wu G. Integrin a6/Akt/Erk signaling is essential for human breast cancer resistance to radiotherapy. Sci Rep. 2016;6:33376.

40. Haas TL, Sciuto MR, Brunetto L, Valvo C, Signore M, Fiori ME, di Martino S, Giannetti S, Morgante L, Boe A, Patrizii M, Warnken U, Schnölzer M, Ciolfi A, Di Stefano C, Biffoni M, Ricci-Vitiani L, Pallini R, De Maria R. Integrin a7 is a functional marker and potential therapeutic target in glioblastoma. Cell Stem Cell. 2017;21(1):35-50.e39.

41. Gupta SK, Oommen S, Aubry MC, Williams BP, Vlahakis NE. Integrin a9 91 promotes malignant tumor growth and metastasis by potentiating epithelial-mesenchymal transition. Oncogene. 2013;32(2):141-50.

42. Munksgaard Thorén M, Chmielarska Masoumi K, Krona C, Huang X, Kundu S, Schmidt L, Forsberg-Nilsson K, Floyd Keep M, Englund E, Nelander S, Holmqvist B, Lundgren-Åkerlund E. Integrin a10, a novel therapeutic target in glioblastoma, regulates cell migration, proliferation, and survival. Cancers (Basel). 2019;11(4):587.

43. Salvo E, Garasa S, Dotor J, Morales X, Pelaez R, Altevogt P, Rouzaut A. Combined targeting of TGF-beta1 and integrin beta3 impairs lymph node metastasis in a mouse model of non-small-cell lung cancer. Mol Cancer. 2014;13:112.

44. Fu Y, Zhang Y, Lei Z, Liu T, Cai T, Wang A, Du W, Zeng Y, Zhu J, Liu Z, Huang JA. Abnormally activated OPN/integrin alphaVbeta3/FAK signalling is responsible for EGFR-TKI resistance in EGFR mutant non-smallcell lung cancer. J Hematol Oncol. 2020;13(1):169.

45. Wang T, Huang J, Vue M, Alavian MR, Goel HL, Altieri DC, Languino $L R$, FitzGerald TJ. alphavbeta3 integrin mediates radioresistance of prostate cancer cells through regulation of survivin. Mol Cancer Res. 2019;17(2):398-408

46. Seguin L, Kato S, Franovic A, Camargo MF, Lesperance J, Elliott KC, Yebra M, Mielgo A, Lowy AM, Husain H, Cascone T, Diao L, Wang J, Wistuba II, Heymach JV, Lippman SM, Desgrosellier JS, Anand S, Weis SM, Cheresh DA. An integrin beta(3)-KRAS-RalB complex drives tumour stemness and resistance to EGFR inhibition. Nat Cell Biol. 2014;16(5):457-68.

47. Sung JS, Kang CW, Kang S, Jang Y, Chae YC, Kim BG, Cho NH. ITGB4mediated metabolic reprogramming of cancer-associated fibroblasts. Oncogene. 2020;39(3):664-76.

48. Jin S, Lee WC, Aust D, Pilarsky C, Cordes N. $\beta 8$ integrin mediates pancreatic cancer cell radiochemoresistance. Mol Cancer Res. 2019;17(10):2126-38.

49. Zhang D, Tang DG. "Splice" a way towards neuroendocrine prostate cancer. EBioMedicine. 2018;35:12-3.

50. Singh A, Settleman J. EMT, cancer stem cells and drug resistance: an emerging axis of evil in the war on cancer. Oncogene. 2010;29(34):4741-51.

51. Zhang D, Tang DG, Rycaj K. Cancer stem cells: regulation programs, immunological properties and immunotherapy. Semin Cancer Biol. 2018;52(Pt 2):94-106.

52. Tang DG. Understanding cancer stem cell heterogeneity and plasticity. Cell Res. 2012;22(3):457-72.

53. Seguin L, Desgrosellier JS, Weis SM, Cheresh DA. Integrins and cancer: regulators of cancer stemness, metastasis, and drug resistance. Trends Cell Biol. 2015;25(4):234-40.

54. Lathia JD, Gallagher J, Heddleston JM, Wang J, Eyler CE, Macswords J, Wu Q, Vasanji A, McLendon RE, Hjelmeland AB, Rich JN. Integrin alpha 6 regulates glioblastoma stem cells. Cell Stem Cell. 2010;6(5):421-32.

55. Lo PK, Kanojia D, Liu X, Singh UP, Berger FG, Wang Q, Chen H. CD49f and CD61 identify Her2/neu-induced mammary tumor-initiating cells that are potentially derived from luminal progenitors and maintained by the integrin-TGF $\beta$ signaling. Oncogene. 2012;31(21):2614-26.
56. Ming XY, Fu L, Zhang LY, Qin YR, Cao TT, Chan KW, Ma S, Xie D, Guan $X Y$. Integrin alpha7 is a functional cancer stem cell surface marker in oesophageal squamous cell carcinoma. Nat Commun. 2016;7:13568.

57. Jahangiri A, Aghi MK, Carbonell WS. beta1 integrin: Critical path to antiangiogenic therapy resistance and beyond. Cancer Res. 2014;74(1):3-7.

58. Schober M, Fuchs E. Tumor-initiating stem cells of squamous cell carcinomas and their control by TGF-beta and integrin/focal adhesion kinase (FAK) signaling. Proc Natl Acad Sci U S A. 2011;108(26):10544-9.

59. Truong HH, Xiong J, Ghotra VP, Nirmala E, Haazen L, Le-Devedec SE, Balcioglu HE, He S, Snaar-Jagalska BE, Vreugdenhil E, Meerman JH, van de Water B, Danen EH: Beta1 integrin inhibition elicits a prometastatic switch through the TGFbeta-miR-200-ZEB network in E-cadherin-positive triple-negative breast cancer. Sci Signal 2014, 7(312): ra15.

60. Kawahara R, Niwa Y, Simizu S. Integrin beta1 is an essential factor in vasculogenic mimicry of human cancer cells. Cancer Sci. 2018;109(8):2490-6.

61. Kowalski-Chauvel A, Gouaze-Andersson V, Baricault L, Martin E, Delmas C, Toulas C, Cohen-Jonathan-Moyal E, Seva C. Alpha6-integrin regulates FGFR1 expression through the ZEB1/YAP1 transcription complex in glioblastoma stem cells resulting in enhanced proliferation and stemness. Cancers (Basel). 2019;11(3):406.

62. Goel HL, Gritsko T, Pursell B, Chang C, Shultz LD, Greiner DL, Norum JH, Toftgard R, Shaw LM, Mercurio AM. Regulated splicing of the alpha6 integrin cytoplasmic domain determines the fate of breast cancer stem cells. Cell Rep. 2014;7(3):747-61.

63. Goel HL, Pursell B, Chang C, Shaw LM, Mao J, Simin K, Kumar P, Vander Kooi CW, Shultz LD, Greiner DL, Norum JH, Toftgard R, Kuperwasser C, Mercurio AM. GLI1 regulates a novel neuropilin-2/a6ß1 integrin based autocrine pathway that contributes to breast cancer initiation. EMBO Mol Med. 2013;5(4):488-508.

64. Zoni E, van der Horst G, van de Merbel AF, Chen L, Rane JK, Pelger RC, Collins AT, Visakorpi T, Snaar-Jagalska BE, Maitland NJ, van der Pluijm G. miR-25 modulates invasiveness and dissemination of human prostate cancer cells via regulation of alphav- and alpha6-integrin expression. Cancer Res. 2015;75(11):2326-36.

65. Boger C, Warneke VS, Behrens HM, Kalthoff H, Goodman SL, Becker T, Rocken C. Integrins alphavbeta3 and alphavbeta5 as prognostic, diagnostic, and therapeutic targets in gastric cancer. Gastric Cancer. 2015;18(4):784-95.

66. Alday-Parejo B, Stupp R, Ruegg C. Are integrins still practicable targets for anti-cancer therapy? Cancers (Basel). 2019;11 (7):978.

67. Dong H, Liu H, Zhou W, Zhang F, Li C, Chen J, Tan C, Tang B, Yu P. GLI1 activation by non-classical pathway integrin alphavbeta3/ERK1/2 maintains stem cell-like phenotype of multicellular aggregates in gastric cancer peritoneal metastasis. Cell Death Dis. 2019;10(8):574.

68. Monnier Y, Farmer P, Bieler G, Imaizumi N, Sengstag T, Alghisi GC, Stehle JC, Ciarloni L, Andrejevic-Blant S, Moeckli R, Mirimanoff RO, Goodman SL, Delorenzi M, Ruegg C. CYR61 and alphaVbeta5 integrin cooperate to promote invasion and metastasis of tumors growing in preirradiated stroma. Cancer Res. 2008;68(18):7323-31.

69. Berghoff AS, Kovanda AK, Melchardt T, Bartsch R, Hainfellner JA, Sipos B, Schittenhelm J, Zielinski CC, Widhalm G, Dieckmann K, Weller M, Goodman SL, Birner P, Preusser M. alphavbeta3, alphavbeta5 and alphavbeta6 integrins in brain metastases of lung cancer. Clin Exp Metastasis. 2014;31(7):841-51.

70. Zhu Z, Mesci P, Bernatchez JA, Gimple RC, Wang X, Schafer ST, Wettersten HI, Beck S, Clark AE, Wu Q, Prager BC, Kim LJY, Dhanwani R, Sharma S, Garancher A, Weis SM, Mack SC, Negraes PD, Trujillo CA, Penalva LO, Feng J, Lan Z, Zhang R, Wessel AW, Dhawan S, Diamond MS, Chen CC, Wechsler-Reya RJ, Gage FH, Hu H, et al. Zika Virus Targets Glioblastoma Stem Cells through a SOX2-Integrin alphavbeta5 Axis. Cell Stem Cell. 2020;26(2):187-204e110.

71. Malric L, Monferran S, Delmas C, Arnauduc F, Dahan P, Boyrie S, Deshors P, Lubrano V, Da Mota DF, Gilhodes J, Filleron T, Siegfried A, Evrard S, Kowalski-Chauvel A, Moyal EC-J, Toulas C, Lemarié A. Inhibiting integrin $\beta 8$ to differentiate and radiosensitize glioblastoma-initiating cells. Mol Cancer Res 2019;17(2):384-97.

72. Guerrero PA, Tchaicha JH, Chen Z, Morales JE, McCarty N, Wang Q, Sulman EP, Fuller G, Lang FF, Rao G, McCarty JH. Glioblastoma stem cells 
exploit the alphavbeta8 integrin-TGFbeta1 signaling axis to drive tumor initiation and progression. Oncogene. 2017;36(47):6568-80.

73. Casari I, Howard JA, Robless EE, Falasca M. Exosomal integrins and their influence on pancreatic cancer progression and metastasis. Cancer Lett. 2021:507:124-34

74. Adem B, Vieira PF, Melo SA. Decoding the Biology of Exosomes in Metastasis. Trends Cancer. 2020;6(1):20-30.

75. Fedele C, Singh A, Zerlanko BJ, lozzo RV, Languino LR. The av $B 6$ integrin is transferred intercellularly via exosomes. J Biol Chem. 2015;290(8):4545-51.

76. Quaglia F, Krishn SR, Daaboul GG, Sarker S, Pippa R, Domingo-Domenech J, Kumar G, Fortina P, McCue P, Kelly WK, Beltran H, Liu Q, Languino LR. Small extracellular vesicles modulated by aV $\beta 3$ integrin induce neuroendocrine differentiation in recipient cancer cells. J Extracell Vesicles. 2020;9(1):1761072.

77. Hoshino A, Costa-Silva B, Shen TL, Rodrigues G, Hashimoto A, Tesic Mark M, Molina H, Kohsaka S, Di Giannatale A, Ceder S, Singh S, Williams C, Soplop N, Uryu K, Pharmer L, King T, Bojmar L, Davies AE, Ararso Y, Zhang T, Zhang H, Hernandez J, Weiss JM, Dumont-Cole VD, Kramer K, Wexler LH, Narendran A, Schwartz GK, Healey JH, Sandstrom P, et al. Tumour exosome integrins determine organotropic metastasis. Nature. 2015;527(7578):329-35.

78. Bierie B, Pierce SE, Kroeger C, Stover DG, Pattabiraman DR, Thiru P, Liu Donaher J, Reinhardt F, Chaffer CL, Keckesova Z, Weinberg RA. Integrin- $\beta 4$ identifies cancer stem cell-enriched populations of partially mesenchymal carcinoma cells. Proc Natl Acad Sci U S A. 2017;114(12):E2337-e2346.

79. Masugi Y, Yamazaki K, Emoto K, Effendi K, Tsujikawa H, Kitago M, Itano $\mathrm{O}$, Kitagawa Y, Sakamoto M. Upregulation of integrin $\beta 4$ promotes epithelial-mesenchymal transition and is a novel prognostic marker in pancreatic ductal adenocarcinoma. Lab Invest. 2015;95(3):308-19.

80. Yoshioka T, Otero J, Chen Y, Kim YM, Koutcher JA, Satagopan J, Reuter V, Carver B, de Stanchina E, Enomoto K, Greenberg NM, Scardino PT, Scher $\mathrm{HI}$, Sawyers CL, Giancotti FG. $\beta 4$ Integrin signaling induces expansion of prostate tumor progenitors. J Clin Invest. 2013;123(2):682-99.

81. Vaillant F, Asselin-Labat ML, Shackleton M, Forrest NC, Lindeman GJ, Visvader JE. The mammary progenitor marker CD61/beta3 integrin identifies cancer stem cells in mouse models of mammary tumorigenesis. Cancer Res. 2008;68(19):7711-7.

82. Malric L, Monferran S, Delmas C, Arnauduc F, Dahan P, Boyrie S, Deshors P, Lubrano V, Da Mota DF, Gilhodes J, Filleron T, Siegfried A, Evrard S, Kowalski-Chauvel A, Moyal EC, Toulas C, Lemarié A. Inhibiting Integrin $\beta 8$ to Differentiate and Radiosensitize Glioblastoma-Initiating Cells. Mol Cancer Res. 2019;17(2):384-97.

83. Desgrosellier JS, Lesperance J, Seguin L, Gozo M, Kato S, Franovic A, Yebra M, Shattil SJ, Cheresh DA. Integrin av $\beta 3$ drives slug activation and stemness in the pregnant and neoplastic mammary gland. Dev Cell. 2014;30(3):295-308

84. Huang W, Yan Y, Liu Y, Lin M, Ma J, Zhang W, Dai J, Li J, Guo Q, Chen H, Makabel B, Liu H, Su C, Bi H, Zhang J. Exosomes with low miR-34c-3p expression promote invasion and migration of non-small cell lung cancer by upregulating integrin a $2 \beta 1$. Signal Transduct Target Ther. 2020:5(1):39.

85. Wu X, Cai J, Zuo Z, Li J. Collagen facilitates the colorectal cancer stemness and metastasis through an integrin/PI3K/AKT/Snail signaling pathway. Biomed Pharmacother. 2019;114:108708.

86. Moon JH, Rho YS, Lee SH, Koo BS, Lee HJ, Do SI, Cho JH, Eun YG, Park MW, Shin HA, Lim YC. Role of integrin $\beta 1$ as a biomarker of stemness in head and neck squamous cell carcinoma. Oral Oncol. 2019;96:34-41.

87. Lin HC, Wu CL, Chen YL, Huang JS, Wong TY, Yuan K. High-level $\beta 1$-integrin expression in a subpopulation of highly tumorigenic oral cancer cells. Clin Oral Investig. 2014;18(4):1277-84.

88. Ley K, Rivera-Nieves J, Sandborn WJ, Shattil S. Integrin-based therapeutics: biological basis, clinical use and new drugs. Nat Rev Drug Discov. 2016;15(3):173-83.

89. Estevez B, Shen B, Du X. Targeting integrin and integrin signaling in treating thrombosis. Arterioscler Thromb Vasc Biol. 2015;35(1):24-9.

90. González-Suarez I, de Antonio LR, Orviz A, Moreno-García S, Valle-Arcos MD, Matias-Guiu JA, Valencia C, Jorquera Moya M, Oreja-Guevara C. Catastrophic outcome of patients with a rebound after Natalizumab treatment discontinuation. Brain Behav. 2017;7(4):e00671.
91. Chen Q, Manning CD, Millar H, McCabe FL, Ferrante C, Sharp C, Shahied-Arruda L, Doshi P, Nakada MT, Anderson GM. CNTO 95, a fully human anti alphav integrin antibody, inhibits cell signaling, migration, invasion, and spontaneous metastasis of human breast cancer cells. Clin Exp Metastasis. 2008;25(2):139-48.

92. Mullamitha SA, Ton NC, Parker GJ, Jackson A, Julyan PJ, Roberts C, Buonaccorsi GA, Watson Y, Davies K, Cheung S, Hope L, Valle JW, Radford JA, Lawrance J, Saunders MP, Munteanu MC, Nakada MT, Nemeth JA, Davis HM, Jiao Q, Prabhakar U, Lang Z, Corringham RE, Beckman RA, Jayson GC. Phase I evaluation of a fully human anti-alphav integrin monoclonal antibody (CNTO 95) in patients with advanced solid tumors. Clin Cancer Res. 2007;13(7):2128-35.

93. O'Day S, Pavlick A, Loquai C, Lawson D, Gutzmer R, Richards J, Schadendorf D, Thompson JA, Gonzalez R, Trefzer U, Mohr P, Ottensmeier C, Chao D, Zhong B, de Boer CJ, Uhlar C, Marshall D, Gore ME, Lang Z, Hait W, Ho P. A randomised, phase II study of intetumumab, an anti-avintegrin $\mathrm{mAb}$, alone and with dacarbazine in stage IV melanoma. $\mathrm{Br} J$ Cancer. 2011;105(3):346-52.

94. Hussain M, Le Moulec S, Gimmi C, Bruns R, Straub J, Miller K. Differential effect on bone lesions of targeting integrins: randomized phase II trial of abituzumab in patients with metastatic castration-resistant prostate cancer. Clin Cancer Res. 2016:22(13):3192-200.

95. Élez E, Kocáková I, Höhler T, Martens UM, Bokemeyer C, Van Cutsem E, Melichar B, Smakal M, Csőszi T, Topuzov E, Orlova R, Tjulandin S, Rivera F, Straub J, Bruns R, Quaratino S, Tabernero J. Abituzumab combined with cetuximab plus irinotecan versus cetuximab plus irinotecan alone for patients with KRAS wild-type metastatic colorectal cancer: the randomised phase I/II POSEIDON trial. Ann Oncol. 2015;26(1):132-40.

96. Brooks PC, Stromblad S, Klemke R, Visscher D, Sarkar FH, Cheresh DA. Antiintegrin alpha $\vee$ beta 3 blocks human breast cancer growth and angiogenesis in human skin. J Clin Invest. 1995;96(4):1815-22.

97. Mitjans F, Meyer T, Fittschen C, Goodman S, Jonczyk A, Marshall JF, Reyes $\mathrm{G}$, Piulats J. In vivo therapy of malignant melanoma by means of antagonists of alphav integrins. Int J Cancer. 2000;87(5):716-23.

98. Hersey P, Sosman J, O'Day S, Richards J, Bedikian A, Gonzalez R, Sharfman W, Weber R, Logan T, Buzoianu M, Hammershaimb L, Kirkwood JM. A randomized phase 2 study of etaracizumab, a monoclonal antibody against integrin alpha(v)beta(3), + or - dacarbazine in patients with stage IV metastatic melanoma. Cancer. 2010;116(6):1526-34.

99. Bhaskar V, Zhang D, Fox M, Seto P, Wong MH, Wales PE, Powers D, Chao DT, Dubridge RB, Ramakrishnan V. A function blocking anti-mouse integrin alpha5beta1 antibody inhibits angiogenesis and impedes tumor growth in vivo. J TransI Med. 2007;5:61.

100. Bell-McGuinn KM, Matthews CM, Ho SN, Barve M, Gilbert L, Penson RT, Lengyel E, Palaparthy R, Gilder K, Vassos A, McAuliffe W, Weymer S, Barton J, Schilder RJ. A phase II, single-arm study of the anti-a5ß1 integrin antibody volociximab as monotherapy in patients with platinum-resistant advanced epithelial ovarian or primary peritoneal cancer. Gynecol Oncol. 2011;121(2):273-9.

101. Almokadem $S$, Belani CP. Volociximab in cancer. Expert Opin Biol Ther. 2012;12(2):251-7.

102. Mas-Moruno C, Rechenmacher F, Kessler H. Cilengitide: the first anti-angiogenic small molecule drug candidate design, synthesis and clinical evaluation. Anticancer Agents Med Chem. 2010;10(10):753-68.

103. Reardon DA, Fink KL, Mikkelsen T, Cloughesy TF, O'Neill A, Plotkin S, Glantz M, Ravin P, Raizer JJ, Rich KM, Schiff D, Shapiro WR, BurdetteRadoux S, Dropcho EJ, Wittemer SM, Nippgen J, Picard M, Nabors LB. Randomized phase II study of cilengitide, an integrin-targeting arginine-glycine-aspartic acid peptide, in recurrent glioblastoma multiforme. J Clin Oncol. 2008;26(34):5610-7.

104. Stupp R, Hegi ME, Gorlia T, Erridge SC, Perry J, Hong Y-K, Aldape KD, Lhermitte B, Pietsch T, Grujicic D, Steinbach JP, Wick W, Tarnawski R, Nam D-H, Hau P, Weyerbrock A, Taphoorn MJB, Shen C-C, Rao N, Thurzo L, Herrlinger U, Gupta T, Kortmann R-D, Adamska K, McBain C, Brandes AA, Tonn JC, Schnell O, Wiegel T, Kim C-Y, et al. Cilengitide combined with standard treatment for patients with newly diagnosed glioblastoma with methylated MGMT promoter (CENTRIC EORTC 26071-22072 study): a multicentre, randomised, open-label, phase 3 trial. Lancet Oncol. 2014;15(10):1100-8.

105. Cianfrocca ME, Kimmel KA, Gallo J, Cardoso T, Brown MM, Hudes G, Lewis N, Weiner L, Lam GN, Brown SC, Shaw DE, Mazar AP, Cohen RB. 
Phase 1 trial of the antiangiogenic peptide ATN-161 (Ac-PHSCN-NH(2)), a beta integrin antagonist, in patients with solid tumours. Br J Cancer. 2006;94(11):1621-6.

106. Semba T, Funahashi Y, Ono N, Yamamoto Y, Sugi NH, Asada M, Yoshimatsu K, Wakabayashi T. An angiogenesis inhibitor E7820 shows broadspectrum tumor growth inhibition in a xenograft model: possible value of integrin alpha2 on platelets as a biological marker. Clin Cancer Res. 2004;10(4):1430-8.

107. Sawyer MB, Iq Ba LS, Lenz H, Lima C, Rossignol DP, Krivelevich I, Fan J, El-Khoueiry AB. Phase II study of E7820 in combination with cetuximab in subjects (pts) with metastatic and refractory colorectal cancer (CRC). J Clin Oncol. 2010;28(15):3537-3537.

108. Cirkel GA, Kerklaan BM, Vanhoutte F, Van der Aa A, Lorenzon G, Namour F, Pujuguet P, Darquenne S, de Vos FY, Snijders TJ, Voest EE, Schellens $J$ H, Lolkema MP. A dose escalating phase I study of GLPG0187, a broad spectrum integrin receptor antagonist, in adult patients with progressive high-grade glioma and other advanced solid malignancies. Invest New Drugs. 2016;34(2):184-92.

109. Rosenthal MA, Davidson P, Rolland F, Campone M, Xue L, Han TH, Mehta A, Berd Y, He W, Lombardi A. Evaluation of the safety, pharmacokinetics and treatment effects of an alpha(nu)beta(3) integrin inhibitor on bone turnover and disease activity in men with hormone-refractory prostate cancer and bone metastases. Asia Pac J Clin Oncol. 2010;6(1):42-8.

110. Ryu S, Park KM, Lee SH. Gleditsia sinensis Thorn Attenuates the Collagen-based migration of PC3 prostate cancer cells through the suppression of a2 31 integrin expression. Int J Mol Sci. 2016;17(3):328.

111. Lin TH, Tan TW, Tsai TH, Chen CC, Hsieh TF, Lee SS, Liu HH, Chen WC, Tang CH. D-pinitol inhibits prostate cancer metastasis through inhibition of aVB3 integrin by modulating FAK, C-Src and NF-KB pathways. Int J Mol Sci. 2013;14(5):9790-802.

112. Kotha RR, Luthria DL. Curcumin: biological, pharmaceutical, nutraceutical, and analytical aspects. Molecules 2019, 24(16).

113. Gupta SC, Patchva S, Aggarwal BB. Therapeutic roles of curcumin: lessons learned from clinical trials. Aaps J. 2013;15(1):195-218.

114. Choe SR, Kim YN, Park CG, Cho KH, Cho DY, Lee HY. RCP induces FAK phosphorylation and ovarian cancer cell invasion with inhibition by curcumin. Exp Mol Med. 2018;50(4):1-10.

115. Chen X, Hou Y, Tohme M, Park R, Khankaldyyan V, Gonzales-Gomez I, Bading JR, Laug WE, Conti PS. Pegylated Arg-Gly-Asp peptide: 64Cu labeling and PET imaging of brain tumor alphavbeta3-integrin expression. J Nucl Med. 2004;45(10):1776-83.

116. Gaertner FC, Kessler H, Wester HJ, Schwaiger M, Beer AJ. Radiolabelled RGD peptides for imaging and therapy. Eur I Nucl Med Mol Imaging. 2012;39(Suppl 1):S126-138.

117. Sharma R, Valls $P O$, Inglese $M$, Dubash $S$, Chen $M$, Gabra H, Montes $A$, Challapalli A, Arshad M, Tharakan G, Chambers E, Cole T, Lozano-Kuehne JP, Barwick TD, Aboagye EO. [(18)F]Fluciclatide PET as a biomarker of response to combination therapy of pazopanib and paclitaxel in platinum-resistant/refractory ovarian cancer. Eur J Nucl Med Mol Imaging. 2020;47(5):1239-51
118. Eo JS, Jeong JM. Angiogenesis Imaging Using (68)Ga-RGD PET/CT: Therapeutic Implications. Semin Nucl Med. 2016;46(5):419-27.

119. Murphy EA, Majeti BK, Barnes LA, Makale M, Weis SM, Lutu-Fuga K, Wrasidlo W, Cheresh DA. Nanoparticle-mediated drug delivery to tumor vasculature suppresses metastasis. Proc Natl Acad Sci USA. 2008;105(27):9343-8.

120. Bogorad RL, Yin H, Zeigerer A, Nonaka H, Ruda VM, Zerial M, Anderson DG, Koteliansky V. Nanoparticle-formulated siRNA targeting integrins inhibits hepatocellular carcinoma progression in mice. Nat Commun. 2014;5:3869.

121. Heidenreich A, Rawal SK, Szkarlat K, Bogdanova N, Dirix L, Stenzl A, Welslau M, Wang G, Dawkins F, de Boer CJ, Schrijvers D. A randomized, double-blind, multicenter, phase 2 study of a human monoclonal antibody to human av integrins (intetumumab) in combination with docetaxel and prednisone for the first-line treatment of patients with metastatic castration-resistant prostate cancer. Ann Oncol. 2013;24(2):329-36.

122. Vermorken JB, Peyrade F, Krauss J, Mesía R, Remenar E, Gauler TC, Keilholz U, Delord JP, Schafhausen P, Erfán J, Brümmendorf TH, Iglesias L, Bethe U, Hicking C, Clement PM. Cisplatin, 5-fluorouracil, and cetuximab (PFE) with or without cilengitide in recurrent/metastatic squamous cell carcinoma of the head and neck: results of the randomized phase I/II ADVANTAGE trial (phase II part). Ann Oncol. 2014;25(3):682-8.

123. Chen H, Zhao L, Fu K, Lin Q, Wen X, Jacobson O, Sun L, Wu H, Zhang X, Guo Z, Lin Q, Chen X. Integrin a(v) $\beta(3)$-targeted radionuclide therapy combined with immune checkpoint blockade immunotherapy synergistically enhances anti-tumor efficacy. Theranostics. 2019;9(25):7948-60.

124. Ruan S, Lin M, Zhu Y, Lum L, Thakur A, Jin R, Shao W, Zhang Y, Hu Y, Huang S, Hurt EM, Chang AE, Wicha MS, Li Q. Integrin $\beta 4$-targeted cancer immunotherapies inhibit tumor growth and decrease metastasis. Cancer Res. 2020;80(4):771-83.

125. Kwan BH, Zhu EF, Tzeng A, Sugito HR, Eltahir AA, Ma B, Delaney MK, Murphy PA, Kauke MJ, Angelini A, Momin N, Mehta NK, Maragh AM, Hynes RO, Dranoff G, Cochran JR, Wittrup KD. Integrin-targeted cancer immunotherapy elicits protective adaptive immune responses. J Exp Med. 2017;214(6):1679-90.

126. Hosen N, Matsunaga Y, Hasegawa K, Matsuno H, Nakamura Y, Makita M, Watanabe K, Yoshida M, Satoh K, Morimoto S, Fujiki F, Nakajima H, Nakata J, Nishida S, Tsuboi A, Oka Y, Manabe M, Ichihara H, Aoyama Y, Mugitani A, Nakao T, Hino M, Uchibori R, Ozawa K, Baba Y, Terakura S, Wada N, Morii E, Nishimura J, Takeda K, et al. The activated conformation of integrin $\beta(7)$ is a novel multiple myeloma-specific target for CAR T cell therapy. Nat Med. 2017;23(12):1436-43.

\section{Publisher's Note}

Springer Nature remains neutral with regard to jurisdictional claims in published maps and institutional affiliations.

\footnotetext{
Ready to submit your research? Choose BMC and benefit from:

- fast, convenient online submission

- thorough peer review by experienced researchers in your field

- rapid publication on acceptance

- support for research data, including large and complex data types

- gold Open Access which fosters wider collaboration and increased citations

- maximum visibility for your research: over $100 \mathrm{M}$ website views per year
}

At BMC, research is always in progress.

Learn more biomedcentral.com/submissions 